\title{
Post-stroke Intranasal (+)-Naloxone Delivery Reduces Microglial Activation and Improves Behavioral Recovery from Ischemic Injury
}

\author{
Jenni E. Anttila, ${ }^{1}$ Katrina Albert, ${ }^{1}$ Emily S. Wires, ${ }^{2}{ }^{\circ}$ Kert Mätlik, ${ }^{1,3}$ Lisa C. Loram, ${ }^{4}$ Linda R. Watkins, ${ }^{4}$ \\ Kenner C. Rice, ${ }^{2}$ Yun Wang, ${ }^{2,5}$ Brandon K. Harvey, ${ }^{2,}$ and ${ }^{\circ}$ Mikko Airavaara ${ }^{1,2,}$

\section{DOI:http://dx.doi.org/10.1523/ENEURO.0395-17.2018} \\ ${ }^{1}$ Institute of Biotechnology, HiLIFE Unit, University of Helsinki, 00014, Finland, ${ }^{2}$ Intramural Research Program, National Institute \\ on Drug Abuse, IRP, NIH, Baltimore, MD 21224, ${ }^{3}$ Medicum, Department of Pharmacology, University of Helsinki, 00014, \\ Finland, ${ }^{4}$ Department of Psychology \& Neuroscience, University of Colorado, Boulder, CO 80309 , and ${ }^{5}$ Center for \\ Neuropsychiatric Research, National Health Research Institutes, Zhunan, 35053, Taiwan
}

\begin{abstract}
Ischemic stroke is the leading cause of disability, and effective therapeutic strategies are needed to promote complete recovery. Neuroinflammation plays a significant role in stroke pathophysiology, and there is limited understanding of how it affects recovery. The aim of this study was to characterize the spatiotemporal expression profile of microglial activation and whether dampening microglial/macrophage activation post-stroke facilitates the recovery. For dampening microglial/ macrophage activation, we chose intranasal administration of naloxone, a drug that is already in clinical use for opioid overdose and is known to decrease microglia/macrophage activation. We characterized the temporal progression of microglia/macrophage activation following cortical ischemic injury in rat and found the peak activation in cortex $7 \mathrm{~d}$ post-stroke. Unexpectedly, there was a chronic expression of phagocytic cells in the thalamus associated with neuronal loss. (+)-Naloxone, an enantiomer that reduces microglial activation without antagonizing opioid receptors, was administered intranasally starting $1 \mathrm{~d}$ post-stroke and continuing for $7 \mathrm{~d}$. (+)-Naloxone treatment decreased microglia/macrophage activation in the striatum and thalamus, promoted behavioral recovery during the 14-d monitoring period, and reduced neuronal death in the lesioned cortex and ipsilateral thalamus. Our results are the first to show that post-stroke intranasal (+)-naloxone administration promotes short-term functional recovery and reduces microglia/macrophage activation. Therefore, (+)-naloxone is a promising drug for the treatment of ischemic stroke, and further studies should be conducted.
\end{abstract}

Key words: Microglia; middle cerebral artery occlusion; naloxone; NF- $\kappa \mathrm{B}$; secondary injury; stroke

\section{Significance Statement}

Ischemic stroke is one of the leading causes of adult disability, and new drug treatments are needed, as there is no drug that promotes recovery. Neuroinflammation is suggested to play a role in the recovery process. Naloxone is a drug used clinically to treat opioid overdose. Its opioid receptor inactive form, $(+)$-naloxone, is known to reduce the activation of microglia, the immune cells of the brain. We show for the first time that repeated dosing of intranasal (+)-naloxone starting $1 \mathrm{~d}$ after stroke promotes short-term recovery in rats and reduces microglial activation and neuronal loss in the stroke brain. Our finding could be important for future stroke treatment and encourages further testing of (+)-naloxone in stroke patients.

Received November 17, 2017; accepted March 20, 2018; First published April 16, 2018.

The authors declare no competing financial interests.

Author contributions: JEA, BKH, and MA: conception and design; JEA, KA, ESW, KM, LCL, LRW, KCR, YW, BKH, and MA: collection and assembly of data, data analysis and interpretation, manuscript writing; $\mathrm{BKH}$ and $\mathrm{MA}$ : financial support and final approval of manuscript.

This work was supported by Academy of Finland grants: \#250275, \#256398, \#281394, \#309489; Biocentrum Helsinki; Sigrid Jusélius Foundation; EU FP7 GLORIA ID: 602919, 3iRegeneration funded by Tekes, and the National Institute on Drug Abuse, Intramural Research Program at the National Institutes of 


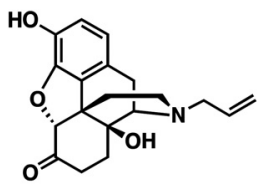

(-)-Naloxone

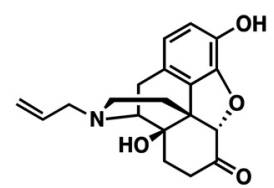

(+)-Naloxone
Figure 1. Chemical structure of $(-)$-naloxone and (+)naloxone enantiomers. $K_{i}$ of $(-)$-naloxone for antagonizing opioid receptors is in the $1 \mathrm{nM}$ range, whereas $(+)$-naloxone has a very low affinity for opioid receptors, with a $K_{i}$ of $10,000 \mathrm{nM}$ (lijima et al., 1978).

\section{Introduction}

Approximately 10 million patients survive a stroke each year; however, there are currently no pharmacological options to promote recovery. Neurologic deficits including impaired use of contralateral limbs, sensory and cognitive deficits, and problems in speaking are the primary cause of disability and remain without effective treatment. Despite increased knowledge of the cellular and molecular mechanisms that mediate damage and recovery after stroke, the development of new drugs for stroke has been unsuccessful (Dirnagl, 2012). Most studies have focused on neuroprotection, and therefore, there is a great need to find novel drug targets and develop new treatments that would improve the recovery from ischemic brain injury by targeting postischemic pathologic mechanisms such as inflammation. Modulation of brain inflammatory cascades following stroke is recognized as a viable therapeutic strategy to promote functional recovery from ischemic brain injury (Endres et al., 2008). However, very few studies have taken this approach, and little is known about recovery from stroke in relation to neuroinflammation.

The drug naloxone, an opiate antagonist, has been clinically used for opioid overdose for nearly 50 years, has anti-inflammatory properties, and can attenuate microglial activation. Naloxone has two stereoisomers, the $(-)$ and $(+)$ enantiomers (Fig. 1). (-)-Naloxone has a high affinity for antagonizing $\mu, \delta$, and $\kappa$ opioid receptors, whereas (+)-naloxone has a very low affinity for opioid receptors (lijima et al., 1978). Clinical reports indicate that intravenously administered (-)-naloxone ameliorates neurologic

Health. KCR was also supported by the National Institute on Alcohol Abuse and Alcoholism. JEA was also funded by Ella and Georg Ehrnrooth Foundation, Päivikki and Sakari Sohlberg Foundation, Alfred Kordelin Foundation, and Orion Research Foundation.

${ }^{\star}$ B.K.H. and M.A. have equal contribution for the senior corresponding author position.

Acknowledgments: Congjun Zheng, Paula Collin-Olkkonen, and Suvi Pöyhönen are acknowledged for technical assistance.

Correspondence should be addressed to either Brandon K. Harvey, PhD, National Institute on Drug Abuse, Intramural Research Program, National Institutes of Health, 251 Bayview Blvd, Baltimore, MD 21224, E-mail: bharvey@intra.nida.nih.gov or Mikko Airavaara, PhD, Institute of Biotechnology, HiLIFE unit, P.O. Box 56 (Viikinkaari 5D), 00014 University of Helsinki, Finland; E-mail: mikko.airavaara@helsinki.fi.

DOI:http://dx.doi.org/10.1523/ENEURO.0395-17.2018

Copyright (C) 2018 Anttila et al.

This is an open-access article distributed under the terms of the Creative Commons Attribution 4.0 International license, which permits unrestricted use, distribution and reproduction in any medium provided that the original work is properly attributed. deficits in acute stroke (Baskin and Hosobuchi, 1981; Jabaily and Davis, 1984). Studies examining the neuroprotective effect of (-)-naloxone in rat focal cerebral ischemia also showed a significant reduction in neuronal loss and inflammation (Chen et al., 2001; Liao et al., 2003), but $(+)$-naloxone did not affect infarction volume when administered before ischemia. These differences between $(-)$ and $(+)$ isoforms suggest a role for opioid receptor antagonism in the neuroprotective effect (Liao et al., 2003). However, both enantiomers have been shown to reduce the number of activated microglia in a rat model of neuropathic pain (Hutchinson et al., 2008) and to inhibit superoxide production from microglia, and subsequent neurodegeneration, by interacting with NADPH oxidase (Liu et al., 2002; Qin et al., 2005; Wang et al., 2012). Also, both naloxone enantiomers reduce lipopolysaccharide (LPS)-induced microglial activation and protect neurons from LPS-induced neurodegeneration (Liu et al., 2000a, b, c). LPS signaling in microglia/macrophages requires Toll-like receptor 4 (TLR4) that is expressed abundantly on microglia (Lehnardt et al., 2003). Both (-)- and (+)-naloxone enantiomers decrease LPS-induced TLR4 signaling (Hutchinson et al., 2008; Wang et al., 2016) and both have been shown to antagonize the TLR4 coreceptor MD2 (Hutchinson et al., 2012). TLR4 activation leads to activation of NF- $\kappa B$ and production of pro-inflammatory cytokines, interferons, and reactive oxygen/nitrogen species. TLR4 deficiency is neuroprotective in ischemic stroke in mice (Kilic et al., 2008), and increased TLR4 expression is associated with more severe stroke in patients (Yang et al., 2008).

Collectively, these studies suggest that naloxone can modulate immune and glial responses and has therapeutic potential in stroke. However, its effects on post-stroke microglial activation and recovery have not been studied. Because $(+)$ and $(-)$ forms have similar efficacy in reducing microglial activation, the advantage of the $(+)$-form is that side effects from antagonizing opioid receptors can be avoided. Thus, we aimed to study whether prolonged post-stroke administration of $(+)$-naloxone in rats would promote recovery and whether this recovery is associated with altered levels of activated microglia/macrophages. Furthermore, we took an approach of intranasal administration, since recent advances with intranasal naloxone formulations have provided excellent bioavailability and enabled easy administration in patients. We first characterized the neuroinflammatory response following focal cortical ischemia-reperfusion injury, since it is not well studied. As microglia/macrophages showed activation already on day 2 post-stroke in the ischemic cortex and maximum activation was observed at day 7 , we administered $(+)$-naloxone during this accumulation period. Here we show how post-stroke intranasal (+)-naloxone promoted behavioral recovery during the short 14-d testing period and decreased microglia/macrophage activation and neuronal loss.

\section{Materials and Methods}

\section{Animals}

Adult male Sprague-Dawley rats (200-250 g; Charles River) were maintained under a 12-h light-dark cycle. 
Food and water were freely available in the home cage. Experimental procedures were approved by the NIDA Animal Care and Use Committee or by the National Animal Experiment Board of Finland (protocol approval number ESAVI/5459/04.10.03/2011) and followed the guidelines of the "Guide for the Care and Use of Laboratory Animals" (National Institutes of Health publication, 1996) and local laws and regulations.

\section{Cortical stroke model in rats with distal middle cerebral artery occlusion}

To model focal cortical ischemic stroke in rats, the three-vessel occlusion method was used. In this model, the stroke damage is restricted to the cortex, and the relative size of the stroke is close to that of an average human stroke (Delavaran et al., 2013). Ligation of the right middle cerebral artery (MCA) and common carotid arteries (CCAs) bilaterally was performed as described previously (Chen et al., 1986; Airavaara et al., 2009, 2010; Harvey et al., 2011). Briefly, rats were anesthetized with chloral hydrate $0.4 \mathrm{~g} / \mathrm{kg}$ intraperitoneally (i.p.). The bilateral CCAs were identified and isolated through a ventral midline cervical incision. The rats were placed in a stereotaxic apparatus, and a craniotomy was performed to expose the right MCA. The MCA was ligated with a 10-0 suture, and bilateral CCAs were ligated with nontraumatic arterial clamps. After 60 or 90 min of ischemia, the suture around the MCA and arterial clips on CCAs were removed to begin reperfusion. After recovery from anesthesia, rats were returned to their home cage. Body temperature during and after surgery was maintained at $37^{\circ} \mathrm{C}$.

\section{Intranasal administration of $(-)$-naloxone and $(+)$ - naloxone}

$(-)$-Naloxone and (+)-naloxone were synthesized in the laboratory of Dr. Kenner Rice (NIDA IRP, NIH). Dosing was estimated from a previously published study (Hutchinson et al., 2008). Drugs were administered intranasally under isoflurane anesthesia (Anesthesia Auto Flow System; E-Z Anesthesia) starting from post-stroke day 1 and were continued at 12-h intervals for $7 \mathrm{~d}$, a total of 14 times. Briefly, animals were placed in the induction chamber for $1-1.5 \mathrm{~min}$, and $5 \%$ isoflurane was delivered at $1000 \mathrm{cc} /$ min. Animals were transferred to the nose cone where they received $1.5 \%$ isoflurane delivered at $500 \mathrm{cc} / \mathrm{min}$ for $30 \mathrm{~s}$ before intranasal naloxone delivery. To ensure maximal delivery, animals remained in supine position during naloxone administration. When the animals regained consciousness, they were returned to the home cage. Naloxone solution was prepared fresh daily in sterile ultrapure water and stored at room temperature between administrations. Using a Rainin LTS L-20 pipette and sterile pipette tips, $10 \mu \mathrm{l}$ drug or vehicle was administered into each nostril as described (Luo et al., 2013).

\section{Implantation of mini-osmotic pumps for continuous (+)-naloxone delivery}

Two days after distal middle cerebral artery occlusion (dMCAo) surgery, the rats were anaesthetized with chloral hydrate $(0.4 \mathrm{mg} / \mathrm{kg}$ i.p.) for mini-osmotic pump implantation (Alzet; model 2002). The pump was implanted under the skin, and the catheter was inserted into the right ventricle. The pumps were filled with vehicle (sterile, ultrapure water) or (+)-naloxone $96 \mathrm{mg} / \mathrm{ml}$. The pumping rate was $0.5 \mu \mathrm{l} / \mathrm{h}$, and the pumps were left in place for $12 \mathrm{~d}$.

\section{Behavioral analysis}

The elevated body swing test for body asymmetry (Borlongan et al., 1998), modified Bederson's score (Bederson et al., 1986), and measurement of locomotor activity were performed as previously described (Airavaara et al., 2009, 2010). Briefly, body asymmetry was analyzed from 20 consecutive trials by suspending the rats $20 \mathrm{~cm}$ above the testing table by lifting their tails and counting the frequency of initial turnings of the head or upper body contralateral to the ischemic side (the maximum impairment in stroke animals is 20 contralateral turns, whereas naive animals turn in each direction with equal frequency). For Bederson's score, neurologic deficits were scored using the following criteria: 0 , rats extend both forelimbs straight when lifted by the tail, no observable deficit; 1, rat keeps the one forelimb to the breast and extends the other forelimb straight when lifted by the tail; 2, rat shows decreased resistance to lateral push in addition to behavior in score $1 ; 3$, rat twists the upper half of the body when lifted by the tail in addition to behavior in other scores. Locomotor activity was measured for $24 \mathrm{~h}$ by placing the rat in a $42 \times 42 \times 31-\mathrm{cm}$ Plexiglas box with an infrared activity monitor (Accuscan). All behavioral assessments were performed in a blinded manner, and the experimenter did not know group allocation. Body asymmetry and Bederson's score were assessed at the middle of the day, so that the animals had fully recovered from isoflurane anesthesia needed for the period of intranasal administration in the morning and evening.

\section{Histology}

The rats were deeply anaesthetized with pentobarbital (90 mg/kg i.p.) and transcardially perfused with $200 \mathrm{ml}$ saline followed by $500 \mathrm{ml}$ of $4 \%$ paraformaldehyde. Brains were processed for either paraffin or free-floating sections and stained with anti-lba1, anti-CD68, anti-NeuN, antiGFAP, or anti-MBP antibodies.

\section{Immunostaining of paraffin sections}

Brains were postfixed in 4\% paraformaldehyde for $2 \mathrm{~d}$, dehydrated in a series of ethanol and xylene, and embedded in paraffin. Brains were cut into $5-\mu \mathrm{m}$-thick sagittal sections using a Leica HM355S microtome and mounted on Superfrost Plus slides (Thermo Fisher Scientific). Sections were deparaffinized, and antigen retrieval was performed by heating in $0.05 \%$ citraconic anhydride (Sigma-Aldrich), $\mathrm{pH} 7.4$. Endogenous peroxidase activity was blocked with $0.6 \%$ hydrogen peroxide (Sigma-Aldrich), and nonspecific antibody binding was blocked with 1.5\% normal goat or horse serum Vector Laboratories), followed by incubation with primary antibody (rabbit anti-Iba1 1:1000, \#019-19741, RRID:AB_839504, Wako; mouse anti-CD68 1:500, \#MCA341R, RRID:AB_2291300, AbD Serotec; mouse anti-GFAP 1:1000, \#MAB360, RRID: AB_2109815, Millipore; mouse anti-NeuN 1:200, \#MAB377, RRID:AB_2298772, Millipore; and rabbit anti-MBP 1:500, 
\#ab40390, RRID:AB_1141521, Abcam) at $4^{\circ} \mathrm{C}$ overnight. The next day, sections were incubated with secondary antibody (goat anti-rabbit, RRID:AB_2336820, or horse anti-mouse, RRID:AB_2336811, biotinylated secondary antibody 1:200, Vector Laboratories) followed by incubation with avidin-biotin complex (ABC kit, Vector Laboratories). Color was developed using peroxidase reaction with $3^{\prime}, 3^{\prime}$-diaminobenzidine (DAB; RRID:AB_2336382, Vector Laboratories). Cresyl violet staining was used as background staining with anti-CD68. For immunofluorescence staining, goat anti-rabbit Alexa Fluor 488 (1: 500, \#A11034, RRID:AB_2576217, Life Technologies) and goat anti-mouse Alexa Fluor 568 (1:500, \#A11004, RRID: AB_2534072, Life Technologies) were used as secondary antibodies.

\section{Immunostaining of free-floating sections}

Brains were dehydrated in $30 \%$ sucrose at $4^{\circ} \mathrm{C}$ and sectioned coronally into $40-\mu \mathrm{m}$-thick slices using a Leica CM3050 Cryostat. Sections were taken from 2.1 to $-1.0 \mathrm{~mm}$ (striatum) and -2.4 to $-4.0 \mathrm{~mm}$ (thalamus) relative to bregma, then stored in $1 \times$ PBS for short-term storage or cryopreservant for long-term storage (20\% glycerol, $2 \%$ DMSO in $1 \times$ PBS). Sections were blocked with $0.3 \%$ hydrogen peroxidase and 4\% BSA (Sigma-Aldrich) + 0.3\% Triton X-100 (Sigma-Aldrich), then incubated with primary antibody (rabbit anti-lba1 1:2000, RRID:AB_839504; mouse anti-NeuN 1:1000, RRID:AB_2298772) overnight at $4^{\circ} \mathrm{C}$. The next day, sections were incubated with secondary antibody, followed by incubation with avidin-biotin complex and DAB as above.

\section{Unbiased stereological counting of $\mathrm{Iba1}^{+}$cells in the striatum}

Iba1-positive $\left(\mathrm{Iba1}^{+}\right)$cells in the striatum were counted from $40-\mu \mathrm{m}$-thick free-floating sections using unbiased stereology with a stereomicroscope (Olympus BX51) and Stereolnvestigator 6 program (MBF Bioscience) as previously described (Mijatovic et al., 2007). The optical fractionator method, which involves a three-dimensional probe for counting the cell of interest by randomly and systematically sampling each section, was used. It is unbiased, since it does not involve cell size and shape, and is unaffected by tissue processing. Cell population is computed from the volume fraction. The volume fraction consists of information on the thickness of tissue sampled, the number of sections sampled, and the area in each section sampled. Three $40-\mu \mathrm{m}$-thick coronal slices were selected based on their relative location to bregma $(0.2,-0.26$, and $-0.4 /-0.5 \mathrm{~mm})$ to obtain results relatively free of bias in the distribution of the cells. Only lba1 ${ }^{+}$cells with clear microglia morphology were counted. The contralateral and ipsilateral striata were first traced, and then the area was analyzed for each slice. Approximately 60-80 randomly selected sites per area/slice were analyzed to ensure accuracy and minimize error.

\section{Analysis of $\mathrm{CD} 68^{+}, \mathrm{Iba1}^{+}$, and $\mathrm{NeuN}^{+}$cells in the thalamus}

The number of $\mathrm{CD}_{68}{ }^{+}, \mathrm{Iba1}^{+}$, and $\mathrm{NeuN}^{+}$cells in the thalamus was analyzed using Image-Pro Analyzer 7.0 program. Slides were scanned with a 3DHISTECH Pannoramic 250 FLASH II digital slide scanner (scanning service provided by the Institute of Biotechnology, University of Helsinki; http://www.biocenter.helsinki.fi/bi/ histoscanner/index.html), and $10 \times$ magnification images of the thalamus were taken with Pannoramic Viewer version 1.15.3. To estimate the number of immunopositive cells in the ipsilateral thalamus, the thalamus was traced and the Iba1 immunoreactive area was counted from 3-6 coronal sections (in 3 rats, there were only 2 sections counted). The object count of $\mathrm{NeuN}^{+}$cells in the thalamus was counted from 4-6 coronal sections per brain. Sections were taken every $300-400 \mu \mathrm{m}$ between -2.4 and $-4.0 \mathrm{~mm}$ relative to bregma, and an average for each brain was used for further analysis. The average number of $\mathrm{NeuN}^{+}$cells and the lba1 immunoreactive area are expressed as a percentage compared to the contralateral side. To estimate the number of $\mathrm{CD}^{+} 8^{+}$cells in the thalamus, the object count of $\mathrm{CD}^{+} 8^{+}$cells was analyzed from 3-4 sagittal sections per hemisphere, taken every $500 \mu \mathrm{m}$ between 1.9 and $3.4 \mathrm{~mm}$ or -1.9 and $-3.4 \mathrm{~mm}$ relative to bregma, and the average cell count per hemisphere was used for further analysis.

\section{Quantitation of infarction size}

At day 14 post-stroke, the average infarction size was quantified from 6 anti-NeuN-stained coronal brain sections, taken every $800 \mu \mathrm{m}$ between 1.80 and $-3.00 \mathrm{~mm}$ relative to bregma. The area devoid of $\mathrm{NeuN}^{+}$cells and the total area of the brain section were defined in Pannoramic Viewer version 1.15.3. Infarction size is expressed as a percentage of the total area of the section. At day 2 post-stroke, the infarction volume was quantified with 2,3,5-triphenyltetrazolium chloride (TTC) staining from $2-\mathrm{mm}$ brain slices as described previously (Airavaara et al., 2009).

\section{Measurement of TNF- $\alpha$ secretion from microglia/ macrophages isolated from the stroke cortex}

The CD11b immunopositive cortical microglia/macrophages were isolated by magnetic activated cell sorting (MACS). The rats were anesthetized with pentobarbital (90 $\mathrm{mg} / \mathrm{kg}$ i.p.) at $7 \mathrm{~d}$ post-stroke after $90 \mathrm{~min}$ dMCAo and perfused with $200 \mathrm{ml}$ saline. The ischemic cortex and the corresponding contralateral cortex were dissected on ice in HBSS without $\mathrm{Ca}^{2+}$ and $\mathrm{Mg}^{2+}$. The tissue was dissociated using Neural Tissue Dissociation kit (Miltenyi Biotec) and gentleMACS Dissociator (Miltenyi Biotec). After dissociation, the cells were suspended in 0.5\% BSA in PBS and incubated with Myelin Removal Beads II (1:10, Miltenyi Biotec) for $15 \mathrm{~min}$ at $4^{\circ} \mathrm{C}$. The cells were washed and resuspended in $0.5 \%$ BSA in PBS and filtered through an LS column (Miltenyi Biotec) using a QuadroMACS Separator (Miltenyi Biotec). The total effluent was collected and resuspended in 0.5\% BSA with 2 mM EDTA in PBS. The cells were incubated at $4^{\circ} \mathrm{C}$ for $10 \mathrm{~min}$ with mouse anti-CD11b:FITC antibody (1:10, \#MCA275FA, RRID:AB_2129486, AbD Serotec). The cells were washed, resuspended in $0.5 \% \mathrm{BSA}$ with $2 \mathrm{mM}$ EDTA in PBS, and incubated with anti-FITC MicroBeads (1:10, RRID: AB_244371, Miltenyi Biotec) for $15 \mathrm{~min}$ at $4^{\circ} \mathrm{C}$. The cells were washed and resuspended in $0.5 \%$ BSA with $2 \mathrm{~mm}$ EDTA in PBS. The cell suspension was applied to an LS 
column placed on a QuadroMACS Separator, and the magnetically labeled cells were used for additional experiments. The cells were plated on poly-ornithine-coated glass coverslips on a 48-well plate at the density of 30,000 cells/well in DMEM:F12 medium (Life Technologies) containing 10\% FBS and $0.2 \%$ primocin (InvivoGen). LPS or naloxone was added immediately after plating. The culture medium was collected $20 \mathrm{~h}$ later and analyzed using the Rat TNF alpha ELISA Ready-SET-Go! kit (\#88-734022, RRID:AB_2575088, eBioscience). The results are presented from 3 independent experiments. The CD11 $b^{+}$ cells were isolated from 2-3 rats in each experiment. The values for each well within an experiment were normalized to the mean value of the control wells within the corresponding experiment.

\section{Experimental design and statistical analysis}

All the experiments and analyses were performed in a blinded manner. First, the time course of glial activation in the dMCAo model was characterized. To minimize the number of animals needed ( $n=24$ in total; $n=4$ per group), 90-min occlusion time was used to create a robust lesion. Immunostaining of sagittal sections with anti-lba1, anti-CD68, and anti-GFAP antibodies was used to visualize the temporal and spatial distribution of glial cells poststroke. As the dMCAo model is unilateral, the contralateral hemisphere was used as a control after we confirmed that the expression of glial cells in naive brain is similar to the contralateral hemisphere of ischemic brain. For quantitation of $\mathrm{CD} 8^{+}$cells, 3-4 sections per animal per hemisphere were used to result in an average.

Second, to test the efficacy of post-stroke (+)-naloxone $(0.32 \mathrm{mg} / \mathrm{kg} ; n=27)$, repeated dosing (twice a day for 7 d) was used owing to the short half-life of naloxone. To make the setting clinically relevant, the treatment was started $1 \mathrm{~d}$ after stroke and was given intranasally, and a smaller infarct using 60-min dMCAo was induced. Behavioral recovery was monitored for $14 \mathrm{~d}$ with body asymmetry test, Bederson's score, and measurement of spontaneous locomotor activity. Vehicle $(n=25)$ and no-treatment groups $(n=13)$ were used as a control in the behavioral assays. As both naloxone enantiomers have anti-inflammatory effects on microglia, only the (-) form antagonizes opioid receptors. Thus, we included also $(-)$-naloxone $(n=7)$ group in the behavioral assays to provide information about whether (+)- and (-)-naloxone have similar effects on recovery. The dose-response of $(+)$-naloxone was tested in a separate experiment $(0.0008$ $\mathrm{mg} / \mathrm{kg}, n=8 ; 0.008 \mathrm{mg} / \mathrm{kg}, n=8 ; 0.08 \mathrm{mg} / \mathrm{kg}, n=7 ; 0.8$ $\mathrm{mg} / \mathrm{kg}, n=8$; vehicle, $n=11$ ). The amount of microglial activation in the striatum and thalamus and neuronal loss in the cortex and thalamus were analyzed with immunohistochemistry. For quantitation of $\mathrm{Iba}^{+}$and $\mathrm{NeuN}^{+}$ cells, 3-6 sections from corresponding coronal planes from each animal were used.

Statistical analyses were performed with IBM SPSS Statistics software version 24.0. Normal distribution of each dataset was analyzed by Levene's test for equality of variances and analyzed with either one-way ANOVA or Kruskal-Wallis nonparametric ANOVA, or with Student's $t$ test or nonparametric Mann-Whitney $U$ test in the case of only two groups. One-way ANOVA was followed by Bonferroni's or Dunnett's post hoc test and Kruskal-Wallis test was followed by pairwise comparison with MannWhitney $U$ test. Since the immunohistochemical data did not differ between the vehicle and no treatment groups or between (+)-naloxone doses 0.32 and $0.8 \mathrm{mg} / \mathrm{kg}$, the two groups were combined as one control group and one $(+)$-naloxone group. Statistical significance was considered at $p<0.05$. The results are presented as mean \pm SEM. Superscript letters listed with significance values correspond to the statistical tests shown in Table 1.

\section{Results}

\section{Long-lasting microglial and astrocyte activation in the ipsilateral hemisphere after dMCAo}

We first characterized the neuroinflammatory response in proximal (cortex) and distal (thalamus) regions after transient 90-min dMCAo, and second, tested the efficacy of post-stroke intranasal naloxone treatment in adult rats after 60 min dMCAo. At day 2 post-stroke, microglia/ macrophage activation was observed mainly in the periinfarct region, and few phagocytic $\mathrm{CD} 68^{+}$cells (a marker for activated, phagocytic microglia/macrophages) were present (Fig. 2C, D). Microglia/macrophage activation peaked on day 7 post-stroke in the ischemic cortex, when the core area was filled with lba1 ${ }^{+}$cells (a marker for all microglia/macrophages) and $\mathrm{CD}^{+} 8^{+}$cells having a phagocytic/macrophage-type morphology (Fig. 2Ea, Fa). Microglia/macrophage activation was seen in the ipsilateral striatum starting from post-stroke day 7 (Fig. 2EC). Interestingly, activated microglia/macrophages were aligned along fiber bundles, with a "stream-like" formation along the myelin embedded axons (Fig. 3). Iba $1^{+}$cells with activated morphology were evident in the ipsilateral thalamus at day 7 post-stroke, but only a few cells were $\mathrm{CD}^{+}{ }^{+}$(Fig. 2Ed, Fd, P). CD68 immunoreactivity increased in the ipsilateral thalamus after post-stroke day 7 , peaked at days $14-28$, and remained elevated until day $112\left(H(11)=41.5, p<0.001,{ }^{a}\right.$ Kruskal-Wallis, Fig. $\left.2 P\right)$. These results suggest that inflammation in the thalamus is long lasting and phagocytic cells are present in far distal areas at least 4 mo after stroke (Fig. $2 N d, P$ ). Neuronal loss was observed in the ipsilateral thalamus at poststroke day 14 (Fig. 6B). At 112 d post-stroke, atrophy of the thalamus due to shrinkage of the ipsilateral thalamus was observed (Fig. 2Me, Ne; Fig. 4Ge). Analysis of spatiotemporal activation of $\mathrm{GFAP}^{+}$cells (a marker for astrocytes) revealed a pattern similar to that of microglia/ macrophage activation (Fig. 4). Similarly to microglia, astrocytes in the ischemic core died during the first couple of days. Astrogliosis was found in the peri-infarct area starting from day 2 post-stroke (Fig. $4 B b$ ). There was clear astrocytic scar formation in the peri-infarct region starting from post-stroke day 7 (Fig. $4 \mathrm{Cb}, \mathrm{Ce}$ ). From day 7 onward, astrogliosis was evident in the striatum and even in the thalamus (Fig. 4C-G). Astrogliosis in the ipsilateral thalamus persisted for up to $112 \mathrm{~d}$ post-stroke (Fig. 4Gd, $\mathrm{Ge}$ ), suggesting glial scar formation without local ischemic damage. 
Table 1. Statistical analysis

\begin{tabular}{llll}
\hline Location & Dataset & Data structure & Type of test \\
\hline a & Fig. 2P & $\begin{array}{c}\text { Non-normal distribution } \\
\text { (unequal variances) }\end{array}$ & $\begin{array}{c}\text { Kruskal-Wallis, } \\
\end{array}$ \\
& & Mann-Whitney $U$
\end{tabular}

Fig. 5B Non-normal distribution

Kruskal-Wallis, Mann-Whitney $U$

c

Fig. 5C

Non-normal distribution

Kruskal-Wallis, Mann-Whitney $U$

Non-normal distribution

Kruskal-Wallis, Mann-Whitney $U$

g

h

k

I Fig. $6 A$

m Fig. $6 \mathrm{~B}$

n Fig. $7 A$

익. $7 \mathrm{~B}$

$\mathrm{p}$

q

r

$s$

$\mathrm{t}$

v
Fig. $5 \mathrm{E}$

Non-normal distribution

Kruskal-Wallis, Mann-Whitney U

One-way ANOVA Bonferroni Kruskal-Wallis, Mann-Whitney $U$ Mann-Whitney $U$ Mann-Whitney $U$ $t$ test

One-way ANOVA, Bonferroni

$t$ test

Kruskal-Wallis, Mann-Whitney $U$

One-way ANOVA Bonferroni

Kruskal-Wallis, Mann-Whitney U Kruskal-Wallis, Mann-Whitney $U$ $t$ test Mann-Whitney $U$ Two-way RM ANOVA Mann-Whitney $U$

One-way ANOVA Dunnett
Mann-Whitney $U$
Power

$H(11)=41.5, p=0.000$; ipsilateral hemisphere: $d 2$ vs. $d 7: p=0.021 ; \mathrm{d} 2$ vs. $\mathrm{d} 14: p=0.021$ d2 vs. d28: $p=0.021$; 2 vs. d56: $p=0.021$; d2 vs. d112: $p=0.021 ; \mathrm{d} 7$ vs. d14: $p=$ 0.021 ; $d 7$ vs. $d 28: p=0.021$; $d 7$ vs. d56: $p=0.083$; 7 vs. $112: p=0.083$; d14 vs. d28: $p=1.00 ; \mathrm{d} 14$ vs. d56: $p=0.043 ; \mathrm{d} 14$ vs. d112: $p=0.021 ; \mathrm{d} 28$ vs. d56: $p=0.083 ; \mathrm{d} 28$ vs. d112: $p=0.043$; d56 s. d112: $p=0.773$; ipsilateral vs. contralateral: $\mathrm{d} 2: p=0.773$; $\mathrm{d} 7: p=0.021 ; \mathrm{d} 14: p=0.021 ; \mathrm{d} 28: p=0.021 ; \mathrm{d} 56: p=0.021 ; \mathrm{d} 112: p=0.021$

d1: $H(2)=2.26, p=0.323 ; \mathrm{d} 3: H(2)=4.93, p=0.085 ; \mathrm{d} 7: H(2)=1.29, p=0.524 ; \mathrm{d} 10$ : $H(2)=15.5, p=0.000$; NT vs. (+)-Nal: $p=0.006$; Veh vs. $(+)-\mathrm{Nal}: p=0.000$; NT vs. Veh: $p=0.651$; d14: $H(2)=12.3, p=0.002$; NT vs. $(+)-N a l: p=0.012$; Veh vs. $(+)-N a l:$ $p=0.001 ;$ NT vs. Veh: $p=0.485$

d1: $H(2)=3.25, p=0.197 ; \mathrm{d} 3: H(2)=6.92, p=0.032 ;$ NT vs. (+)-Nal: $p=0.017$; Veh vs. (+)-Nal: $p=0.059$; NT vs. Veh: $p=0.393$; $7: H(2)=3.26, p=0.196 ; \mathrm{d} 10: H(2)=15.4$, $p=0.000$; NT vs. (+)-Nal: $p=0.002$; Veh vs. (+)-Nal: $p=0.002$; NT vs. Veh: $p=0.203$ d14: $H(2)=19.1, p=0.000$; NT vs. (+)-Nal: $p=0.000$; Veh vs. (+)-Nal: $p=0.000$; NT vs. Veh: $p=0.209$

$H(4)=15.1, p=0.004 ;$ Veh vs. $8 \times 10^{-4}: p=0.206$; Veh vs. $8 \times 10^{-3}: p=0.966 ;$ Veh vs. $8 \times 10^{-2}: p=0.002$; Veh vs. $8 \times 10^{-1}: p=0.059 ; 8 \times 10^{-4}$ vs. $8 \times 10^{-3}: p=0.552 ; 8$ $\times 10^{-4}$ vs. $8 \times 10^{-2}: p=0.001 ; 8 \times 10^{-4}$ vs. $8 \times 10^{-1}: p=0.019 ; 8 \times 10^{-3}$ vs. $8 \times$ $10^{-2}: p=0.031 ; 8 \times 10^{-3}$ vs. $8 \times 10^{-1}: p=0.142 ; 8 \times 10^{-2}$ vs. $8 \times 10^{-1}: p=0.488$

$H(4)=6.38, p=0.041$; Veh vs. $8 \times 10^{-4}: p=0.690$; Veh vs. $8 \times 10^{-3}: p=0.487$; Veh vs. $8 \times 10^{-2}: p=0.016 ;$ Veh vs. $8 \times 10^{-1}: p=0.038 ; 8 \times 10^{-4}$ vs. $8 \times 10^{-3}: p=0.314 ; 8$ $\times 10^{-4}$ vs. $8 \times 10^{-2}: p=0.006 ; 8 \times 10^{-4}$ vs. $8 \times 10^{-1}: p=0.025 ; 8 \times 10^{-3}$ vs. $8 \times$ $10^{-2}: p=0.144 ; 8 \times 10^{-3}$ vs. $8 \times 10^{-1}: p=0.208 ; 8 \times 10^{-2}$ vs. $8 \times 10^{-1}: p=0.730$ $F(2,42)=0.054$; NT vs. (+)-Nal: $p=0.064$; Veh vs. (+)-Nal: $p=0.242$; NT vs. Veh: $p=1.00$

$H(2)=6.82, p=0.033 ;$ NT vs. $(+)-\mathrm{Nal}: p=0.004$; Veh vs. $(+)-\mathrm{Nal}: p=0.243$; NT vs. Veh: $p$ $=0.313$

$\mathrm{d} 1: p=0.663 ; \mathrm{d} 3: p=0.663 ; \mathrm{d} 7: p=0.963 ; \mathrm{d} 10: p=0.001 ; \mathrm{d} 14: p=0.000$

$\mathrm{d} 1: p=0.159 ; \mathrm{d} 3: p=0.401 ; \mathrm{d} 7: p=0.565 ; \mathrm{d} 10: p=0.002 ; \mathrm{d} 14: p=0.005$

$\mathrm{d} 7: \mathrm{t}(16)=0.47, p=0.647 ; \mathrm{d} 14: \mathrm{t}(16)=0.06, p=0.953$

d7: $F(2,59)=5.27, p=0.008$; NT vs. $(+)$-Nal: $p=0.574$; Veh vs. $(+)-\mathrm{Nal}: p=0.113$; NT vs. Veh: $p=0.009 ; \mathrm{d} 14: F(2,62)=1.79, p=0.175$

$\mathrm{t}(26)=2.51, p=0.019$

$H(2)=11.4, p=0.003$; Naïve vs. Ctrl: $p=0.002$; Naïve vs. (+)-Nal: $p=0.157$; Ctrl vs. $(+)-$ Nal: $p=0.036$

$F(2,31)=8.63, p=0.001$; Naïve vs. Ctrl: $p=0.003$; Naïve vs. (+)-Nal: $p=1.00$; Ctrl vs. $(+)-$ Nal: $p=0.013$

$H(2)=5.77, p=0.056$

$H(2)=17.6, p=0.000$; Naïve vs. Ctrl: $p=0.000$; Naïve vs. (+)-Nal: $p=0.001$; Ctrl vs. $(+)-$ Nal: $p=0.027$

$\mathrm{t}(13)=0.89, p=0.389$

$\mathrm{d} 2: p=0.861 ; \mathrm{d} 6: p=0.825 ; \mathrm{d} 10: p=0.279 ; \mathrm{d} 16: p=0.066$

$\mathrm{d} 1: p=0.800 ; \mathrm{d} 3: p=0.861 ; \mathrm{d} 7: p=0.516 ; \mathrm{d} 10: p=0.391 ; \mathrm{d} 14: p=0.694$

$F(4,52)=0.29, p=0.88$

$p=0.006$

$F(6,54)=2.74, p=0.022 ; 20 \mu \mathrm{M}(-)-\mathrm{Nal}: p=0.669 ; 50 \mu \mathrm{M}(-)-\mathrm{Nal}: p=0.020 ; 100 \mu \mathrm{M}(-)-\mathrm{Nal}:$ $p=0.218 ; 20 \mu \mathrm{M}(+)$-Nal: $p=0.492 ; 50 \mu \mathrm{M}(+)$-Nal: $p=0.637 ; 100 \mu \mathrm{M}(+)-\mathrm{Nal}: p=$ 0.006

(+)-Nal, (+)-naloxone; (-)-Nal, (-)-naloxone; Ctrl, control; d, post-stroke day; NT, no treatment; RM, repeated measures; Veh, vehicle.

\section{Post-stroke treatment with intranasal (+)-naloxone started on day 1 post-stroke promotes short-term behavioral recovery, reduces neuronal loss, and decreases microglial activation}

The efficacy of post-stroke (+)-naloxone treatment was tested in rats $(n=65)$, and treatment was initiated $1 \mathrm{~d}$ after 60 -min dMCAo, before extensive activation of microglia/macrophages, and it was continued for $7 \mathrm{~d}$, i.e., the period when microglia/macrophage activation progresses in the ischemic region. One day post-stroke, the rats were balanced into groups based on their neurologic deficits as measured by body asymmetry and Bederson's score, and (+)-naloxone $(0.32 \mathrm{mg} / \mathrm{kg})$ or vehicle was administered intranasally every $12 \mathrm{~h}$ for $7 \mathrm{~d}$ (i.e., 14 doses per animal, Fig. 5A). To identify the confounding effect of isoflurane, two control groups were included: (i) stroke rats receiving intranasal vehicle (including repeated isoflurane) and (ii) stroke rats with no intranasal treatment and no isoflurane. There were no significant differences in body asymmetry among the groups on days 1,3 , or 7 after dMCAo ${ }^{b}$ (Fig. 5B). However, on days 10 and 14 post-stroke, body asymmetry $(H(2)=15.5, p<0.001$ and $H(2)=12.3, p=0.002$, respectively, ${ }^{\text {b }}$ Kruskal-Wallis) and neurologic deficits $(H(2)=15.4, p<0.001$ and $H(2)=$ 19.1, $p<0.001$, respectively ${ }^{\mathrm{C}}$ ) were significantly reduced in the (+)-naloxone treated rats (Fig. 5B, C). The reduction in body asymmetry $\left(H(4)=15.1, p=0.004,{ }^{d}\right.$ KruskalWallis) and neurologic deficits $\left(H(4)=6.38, p=0.041^{\mathrm{e}}\right.$ ) was dose dependent (Fig. 5D, E). As another indicator of hastened recovery, (+)-naloxone improved locomotor activity at day 14 post-stroke $\left(H(2)=6.82, p=0.033,^{\mathrm{g}}\right.$ Kruskal-Wallis, Fig. 5G). Similarly, (-)-naloxone (0.32 mg/ 

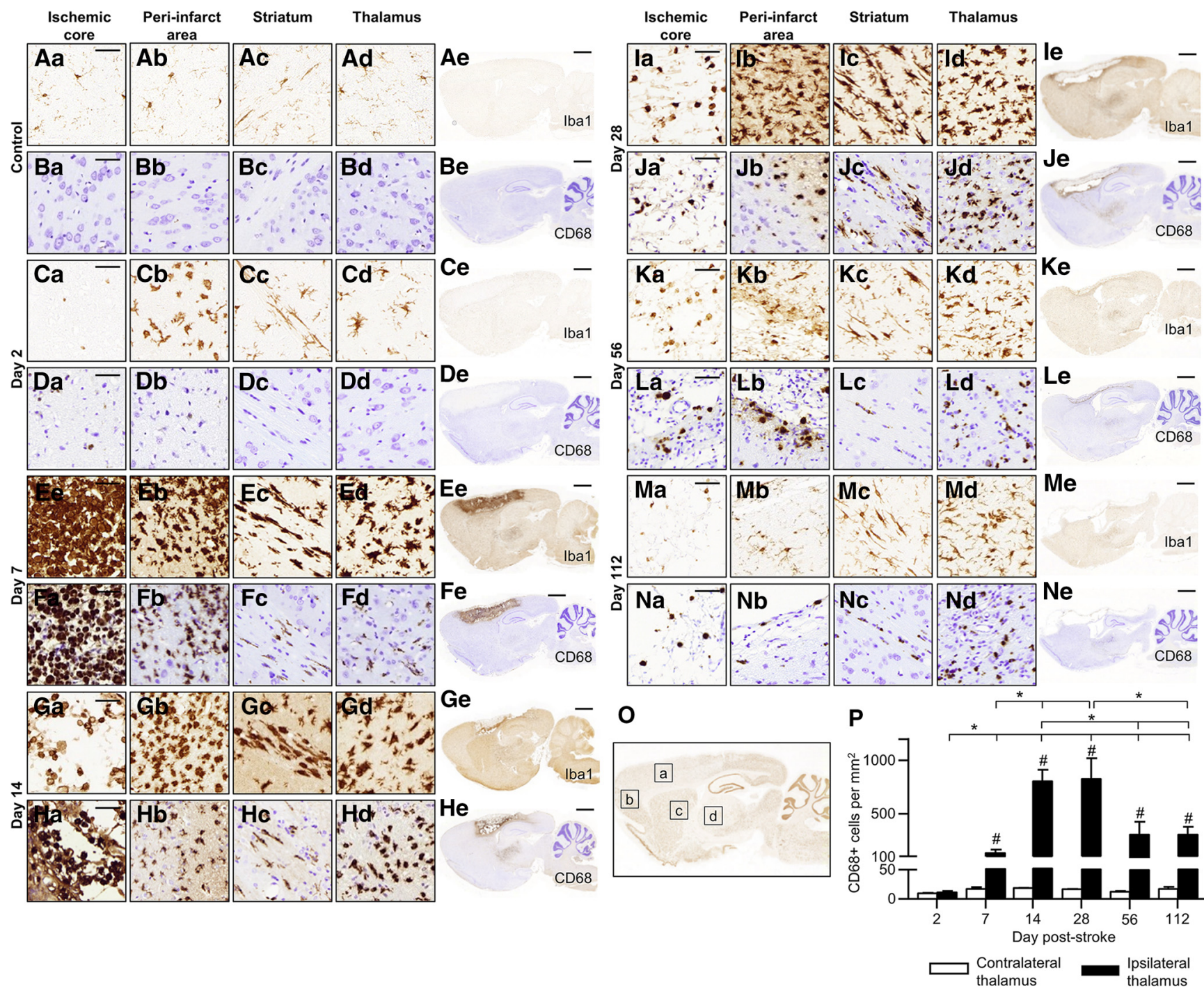

Figure 2. Time course of microglia/macrophage activation after cortical stroke. Representative images of immunostaining for all microglia/macrophages (Iba1) and phagocytic microglia/macrophages (CD68) from ischemic core (a), peri-infarct area (b), striatum (c), thalamus $(\boldsymbol{d})$, and whole brain $(\boldsymbol{e})$ sagittal sections at $2(\boldsymbol{C}, \boldsymbol{D}), 7(\boldsymbol{E}, \boldsymbol{F}), 14(\boldsymbol{G}, \boldsymbol{H}), 28(\boldsymbol{I}, \boldsymbol{J}), 56(\boldsymbol{K}, \boldsymbol{L})$, and $112(\boldsymbol{M}, \boldsymbol{N})$ days after 90 -min dMCAO in rat. Control images $(\boldsymbol{A}, \boldsymbol{B})$ are from the contralateral hemisphere of the stroke brain. Scale bar is $50 \mu \mathrm{m}$ (high magnification) and $2000 \mu \mathrm{m}$ (low magnification). $\boldsymbol{O}$, Example image of anti-NeuN immunostaining at post-stroke day 2 showing in more detail the regions a-d. $\boldsymbol{P}$, Quantitation of $\mathrm{CD} 8^{+}$cells in the thalamus $(\boldsymbol{d})$ at different time points showing the accumulation and clearance of phagocytic microglia/macrophages in the ipsilateral thalamus. $*, p<0.05$ indicates statistical difference between the ipsilateral thalamus at different time points; \#, $p<0.05$ indicates statistical difference between the ipsilateral and contralateral thalamus in each time point, Mann-Whitney $U$ test after Kruskal-Wallis test; $n=4$ in each group. The data represent mean \pm SEM.

$\mathrm{kg}$, intranasally) induced behavioral recovery on days 10 and 14 post-stroke $(n=18 ; p=0.001$ and $p<0.001$, respectively, ${ }^{\mathrm{h}}$ for body asymmetry test; and $p=0.002$ and $p=0.005$, respectively, ${ }^{\prime}$ for Bederson's score, MannWhitney $U$ test; Fig. $5 H, I$ ). It has been reported that continuous administration of the opioid receptor antagonist (-)-naltrexone decreases body weight and appetite (Atkinson, 1984). We found no effect on body weight with naloxone treatment $\mathrm{t}^{\mathrm{j}, \mathrm{k}}$ (Fig. 5J, K).

Post-stroke (+)-naloxone $(0.32-0.8 \mathrm{mg} / \mathrm{kg})$ reduced infarction size on day 14 after dMCAo $(t(26)=2.51, p=$ 0.019 ,' unpaired $t$ test; Fig. $6 A$ ) and prevented delayed neuronal death in the ipsilateral thalamus $(H(2)=11.4$, $p=0.003,{ }^{m}$ Kruskal-Wallis; Fig. $\left.6 B\right)$. We observed a negative correlation between the number of neurons $\left(\mathrm{NeuN}^{+}\right.$cells) in the ipsilateral thalamus and infarction size (Pearson correlation $R=-0.691, p<0.0001$ ), showing that the larger the lesion in the cortex, the more extensive neuronal loss in the thalamus. (+)-Naloxone significantly decreased the $\mathrm{lba} 1^{+}$cell number in the ipsilateral striatum at post-stroke day $14\left(F(2,31)=8.63, p=0.001,{ }^{n}\right.$ oneway ANOVA; Fig. $7 A$ ). There was no statistical difference in the contralateral striatum ${ }^{\circ}$ (Fig. 7B). Similarly, a significant reduction of Iba1 immunoreactivity by $(+)$-naloxone was found in the ipsilateral thalamus $(H(2)=17.6, p<$ $0.001,{ }^{\mathrm{p}}$ Kruskal-Wallis; Fig. $7 C$ ). 
A

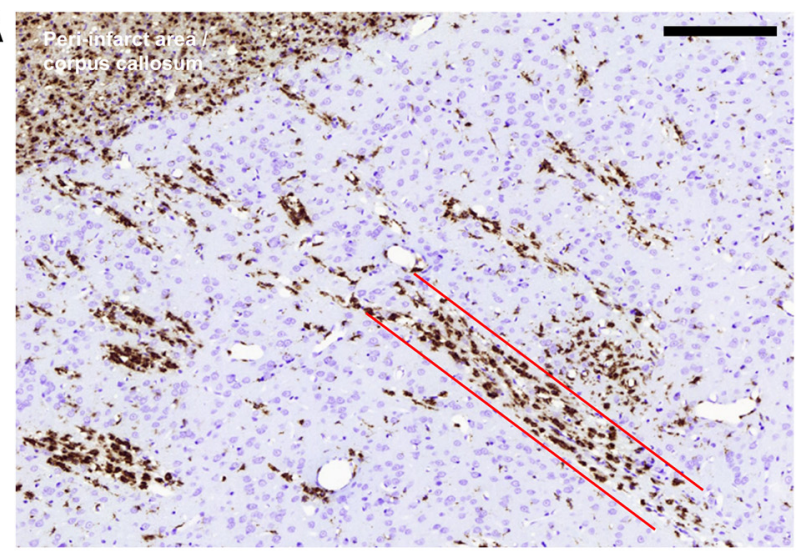

B

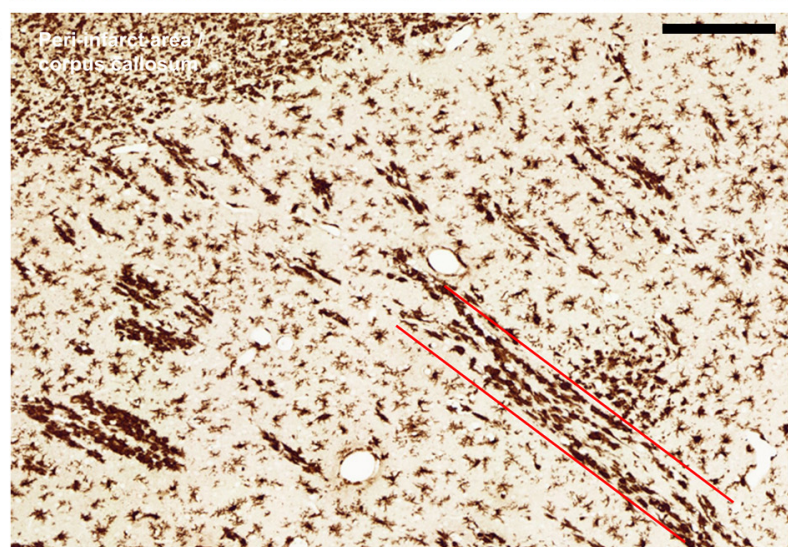

C
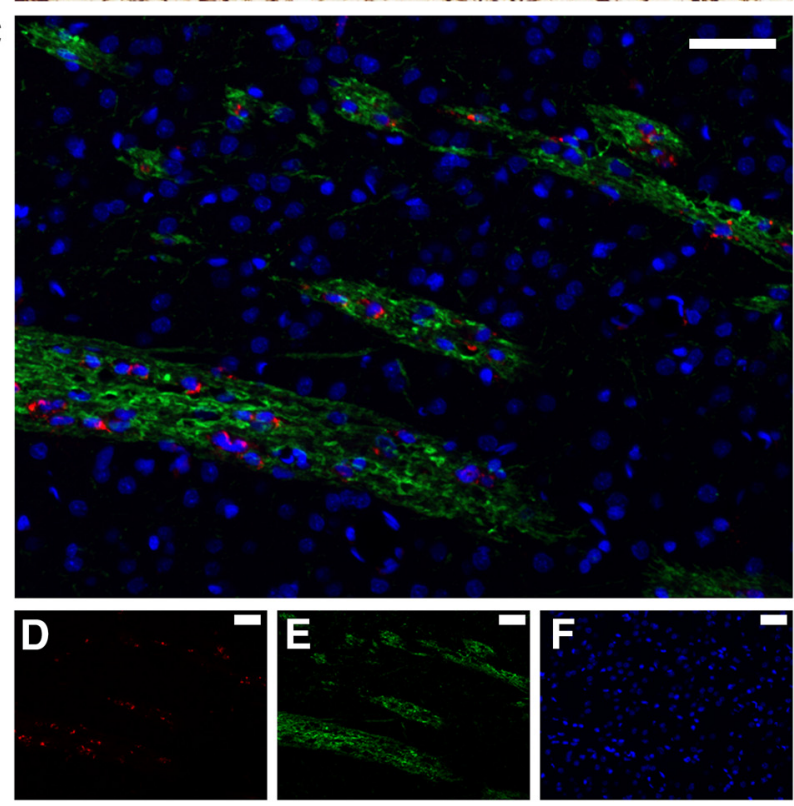

Figure 3. Activated microglia in the striatum are lined up along axonal bundles after cortical stroke. Immunostaining of rat striatum at post-stroke day 14 for phagocytic microglia/ macrophages (CD68; $\boldsymbol{A})$ and all microglia/macrophages (Iba1; B). C-F, Double immunofluorescence staining of rat striatum at post-stroke day 14 for phagocytic microglia/macrophages (CD68; red; $\boldsymbol{D}$ ) and myelin (MBP; green; $\boldsymbol{E}$ ) with DAPI (blue; $\boldsymbol{F}$ ). In $\boldsymbol{A}, \boldsymbol{B}$, scale bar is $200 \mu \mathrm{m}$; in $\boldsymbol{C}-\boldsymbol{F}$, scale bar is $50 \mu \mathrm{m}$.
Pretreatment or delayed post-stroke treatment with $(+)$-naloxone is not beneficial in dMCAo model

We tested the neuroprotective effect of $(+)$-naloxone $(n=15)$ by giving $(+)$-naloxone $(0.32 \mathrm{mg} / \mathrm{kg})$ or vehicle intranasally three times: 12 and $1 \mathrm{~h}$ before 60 -min dMCAo and immediately after reperfusion (Fig. $8 A$ ). The infarction volume was determined by $\Pi T C$ staining $2 \mathrm{~d}$ after stroke. We found no significant differences in the infarction volume between the groups ( $p=0.389,{ }^{9}$ unpaired $t$ test; Fig. $8 B)$. To find out whether more delayed (+)-naloxone treatment would give similar effect on recovery as the treatment started on post-stroke day 1 , we administered (+)naloxone $(0.8 \mathrm{mg} / \mathrm{kg})$ or vehicle intranasally twice daily starting from day 3 after $60-$ min dMCAo and continuing for $7 \mathrm{~d}(n=13$; Fig. $8 C$ ). There was an evident recovery effect over time in the body asymmetry test, but there were no statistically significant differences between the vehicle and (+)-naloxone groups ${ }^{r}$ (Fig. $8 D$ ). On poststroke day 16 , there was a tendency $\left(p=0.066,{ }^{r}\right.$ MannWhitney $U$ test) in the (+)-naloxone group for milder neurologic deficits in the body asymmetry test, but it did not reach statistical significance. To study whether longer, continuous administration of (+)-naloxone would further enhance recovery after 60-min dMCAo, we delivered (+)naloxone $(1.15 \mathrm{mg} / 24 \mathrm{~h})$ or vehicle into the ventricle using mini-osmotic pumps on post-stroke days $2-14(n=15$; Fig. 8E). There was again evident recovery effect in the body asymmetry test, but there were no differences between the vehicle and (+)-naloxone groups ${ }^{\mathrm{s}}$ (Fig. 8F), nor were there any differences in body weight between the groups $^{t}$ (Fig. 8G).

\section{Naloxone decreases TNF- $\alpha$ secretion from microglia/macrophages}

To test whether naloxone enantiomers affect cytokine secretion, we isolated $\mathrm{CD}_{11} \mathrm{~b}^{+}$microglia/macrophages from the infarct area at day 7 post-stroke and measured the secretion of TNF- $\alpha$, a cytokine with well-characterized pro-inflammatory effects downstream of TLR4 signaling. First, we tested whether the isolated cells respond to treatment with LPS by increasing the secretion of TNF- $\alpha$. Overnight treatment with LPS increased the amount of

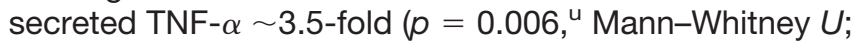
Fig. $9 A$ ), confirming that the isolated cell population had properties characteristic of microglia and macrophages. Overnight treatment with both naloxone enantiomers significantly decreased the amount of TNF- $\alpha$ in the culture medium $\left(F(6,54)=2.74, p=0.022,{ }^{\vee}\right.$ one-way ANOVA; Fig. 9B). (-)-Naloxone $50 \mu \mathrm{M}$ and (+)-naloxone $100 \mu \mathrm{M}$ decreased the unstimulated secretion of TNF- $\alpha$ by $\sim 15 \%$ compared with control.

\section{Discussion}

We show for the first time that intranasal post-stroke administration of naloxone enantiomers reduces inflammation and hastens recovery during short-term behavioral monitoring. Our data support a therapeutic window for initiation of twice daily $(+)$-naloxone treatment between 16 and $36 \mathrm{~h}$ post-stroke and continuing the treatment for $7 \mathrm{~d}$. Our study also indicates that modulation of microglia/ macrophage activation in the ischemic cerebral cortex 

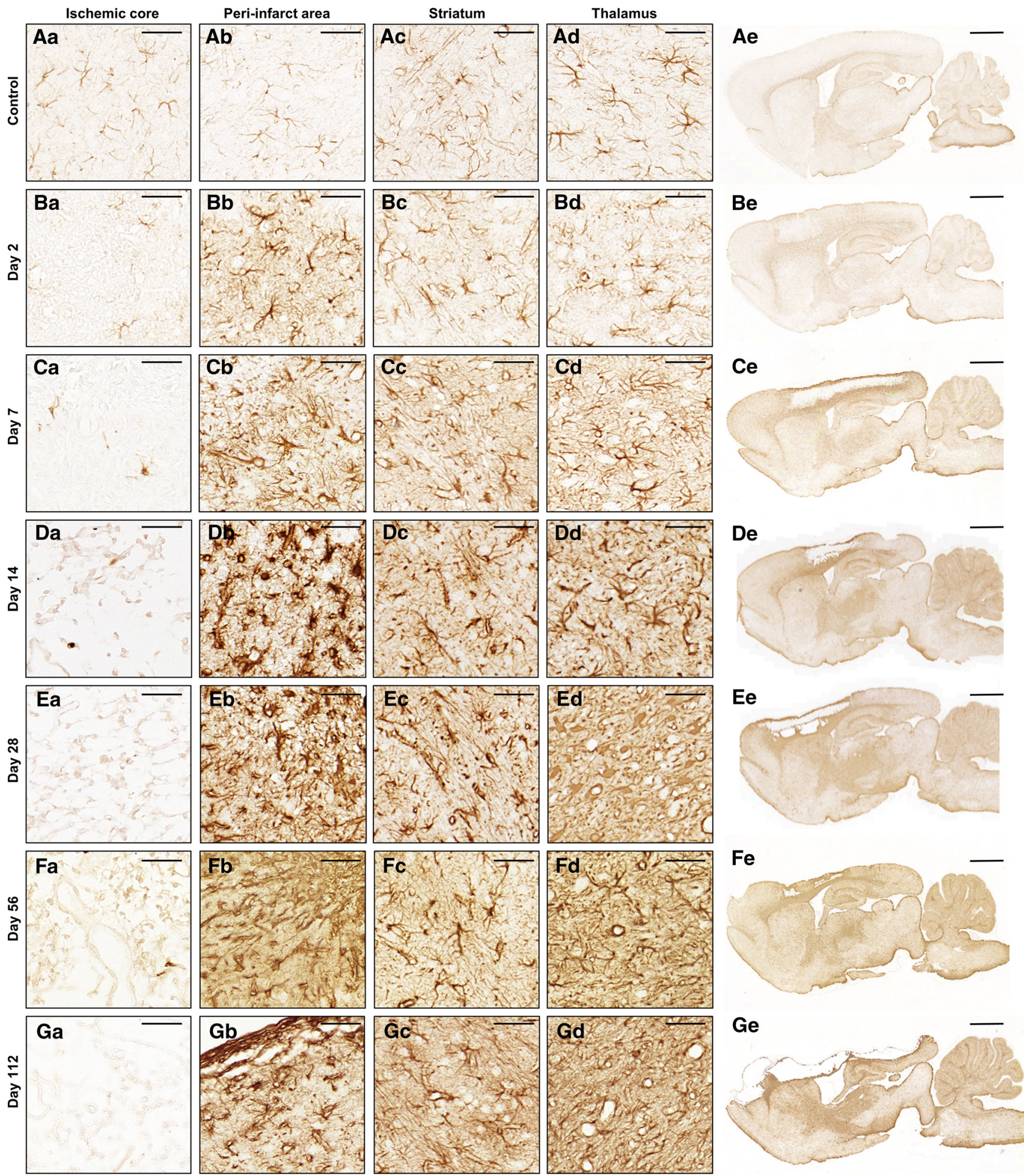

Figure 4. Time course of astrocyte activation after cortical stroke. Representative images of immunostaining for astrocytes (GFAP) from the ischemic core $(\boldsymbol{a})$, peri-infarct area $(\boldsymbol{b})$, striatum $(\boldsymbol{c})$, and thalamus $(\boldsymbol{d})$ at $2(\boldsymbol{B}), 7(\boldsymbol{C}), 14(\boldsymbol{D}), 28(\boldsymbol{E}), 56(\boldsymbol{F})$, and $112(\boldsymbol{G})$ days after $90-\mathrm{min}$ dMCAo in sagittal rat brain paraffin sections. Control images $(\boldsymbol{A})$ are from the contralateral hemisphere of the stroke brain. Scale bar is $50 \mu \mathrm{m}$ in high-magnification images and $2000 \mu \mathrm{m}$ in low-magnification images. The regions analyzed (a-d) are shown in more detail in Fig. 20.

and remote regions in the striatum and thalamus is a potential therapeutic drug strategy. Because microglia/ macrophages can phagocytose viable neurons after isch- emia (Neher et al., 2013), neuroinflammation may lead to secondary neuronal loss. An ischemic brain injury leads to activation of microglia and the release of pro-infla- 
A
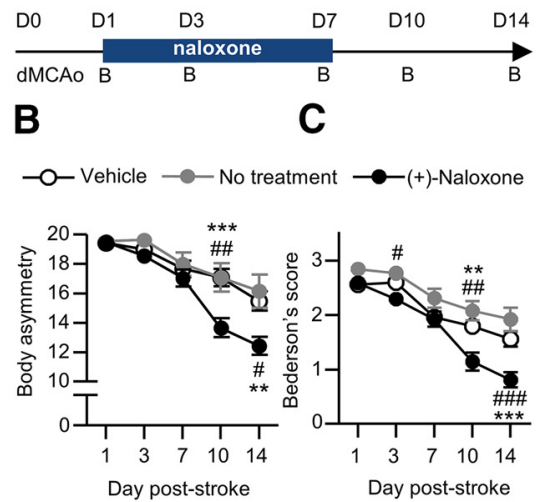

D

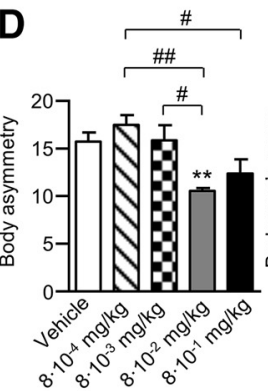

E

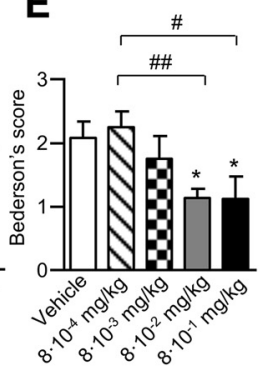

$\mathbf{F}$

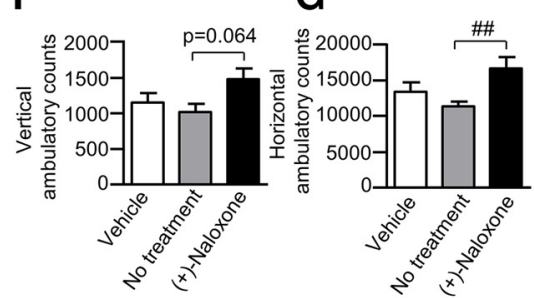

H

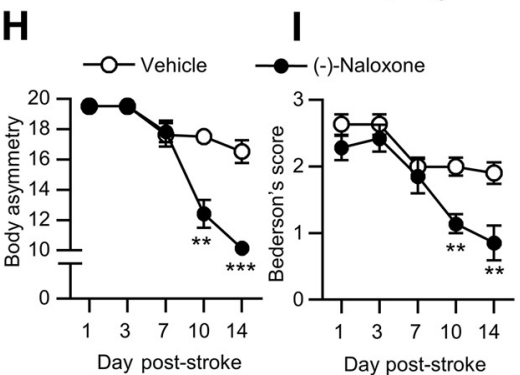

$\mathbf{J}$

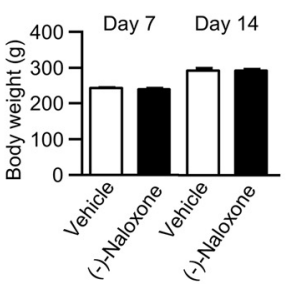

K

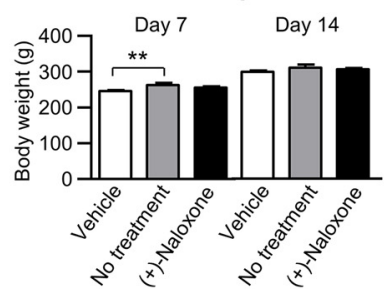

Figure 5. Post-stroke intranasal administration of naloxone enantiomers promotes functional recovery. $\boldsymbol{A}$, Experimental timeline. Intranasal naloxone (or vehicle) was administered twice daily for $7 \mathrm{~d}$ post-stroke. D1-D14, post-stroke days 1-14; B, behavioral assay. B, C, Effects of $(+)$-naloxone $(0.32 \mathrm{mg} / \mathrm{kg} ; n=$ $27)$, vehicle $(n=25)$, and no treatment $(n=13)$ on body asymmetry $(\boldsymbol{B})$ and Bederson's neurologic score test $(\boldsymbol{C})$. **, $p<0.01$ and ***, $p<0.001$ indicate post hoc comparison between $(+)$-naloxone and vehicle groups, and \#, $p<0.05$, \#\#, $p<0.01$, and \#\#\#, $p<0.001$ indicate post hoc analysis between $(+)-$ naloxone and no-treatment groups with Mann-Whitney $U$ test after Kruskal-Wallis test. D, E, Effects of different doses of (+)-naloxone, $0.0008 \mathrm{mg} / \mathrm{kg}(n=8), 0.008 \mathrm{mg} / \mathrm{kg}(n=8), 0.08$ $\mathrm{mg} / \mathrm{kg}(n=7)$, and $0.8 \mathrm{mg} / \mathrm{kg}(n=8)$, compared to vehicle $(n=$ $11)$ on day 14 post-stroke on body asymmetry $(\boldsymbol{D})$ and Bederson's neurologic score test $(\boldsymbol{E}) . *, p<0.05$ and $* *, p<0.01$ indicate pairwise comparison with vehicle; $\#, p<0.05$ and \#\#, $p<$ 0.01 indicate pairwise comparison with other (+)-naloxone doses with Mann-Whitney $U$ test after Kruskal-Wallis test. F, G, Effects of $(+)$-naloxone $(0.32 \mathrm{mg} / \mathrm{kg} ; n=16)$, vehicle $(n=16)$, and no treatment $(n=13)$ on vertical $(\boldsymbol{F})$ and horizontal $(\boldsymbol{G})$ activity measured for $24 \mathrm{~h}$ on day 14 . \#\#, $p<0.01$, MannWhitney $U$ test after Kruskal-Wallis test. $\boldsymbol{H}-\boldsymbol{J}$, Effects of $(-)$ naloxone $(0.32 \mathrm{mg} / \mathrm{kg} ; n=7)$ and vehicle $(n=11)$ on body asymmetry test $(\boldsymbol{H})$, Bederson's neurologic score test $(\boldsymbol{I})$, and body weight $(\boldsymbol{J})$. **, $p<0.01$ and $* * *, p<0.001$ indicate comparison with vehicle group with Mann-Whitney $U$ test. $\boldsymbol{K}$, Effects of $(+)$-naloxone $(0.32 \mathrm{mg} / \mathrm{kg}, n=27)$, vehicle $(n=25)$, and no treatment $(n=13)$ on body weight on days 7 and 14 post-stroke. **, $p<0.01$, one-way ANOVA, Bonferroni's post hoc test. The data represent mean \pm SEM.

mmatory factors and further potentiates neuronal damage days to weeks after dMCAo (Dirnagl et al., 1999). It has been suggested that during an ischemic event, the brain remains in a continual state of neurotoxicity and microglia become overactivated, releasing pro-inflammatory factors that can contribute to further damage (Glass et al., 2010). It is known that overreactive microglia can cause increased levels of cytokines, specifically TNF- $\alpha$ and interleukin-1 $\beta$ and -6 (Lee et al., 1993; Block et al., 2007). Therefore anti-inflammatory drugs, such as minocycline, have been used to alleviate this neuroinflammation and improve stroke outcome (Yrjanheikki et al., 1999). Liebigt et al. (2012) have shown that post-stroke application of minocycline and indomethacin in rats, combined with rehabilitative training, produces improved functional recovery compared with training alone.

Our data indicate that twice-a-day post-stroke treatment with $(+)$-naloxone for a week improves short-term behavioral recovery and reduces neuronal damage and infarction size. The behavioral effect of (+)-naloxone correlated with suppression of activated microglia in the striatum and thalamus and was not observed until day 10 post-stroke, which suggests that $(+)$-naloxone targets delayed post-stroke pathophysiological mechanisms such as inflammation. The administration of $(+)$-naloxone was targeted to the period when the number of activated microglia/macrophages is peaking in the cerebral cortex and before microglial activation is evident in the striatum or thalamus. We therefore propose that dampening microglia/macrophage activation with post-stroke (+)naloxone restricts inflammation to limit associated lesion 

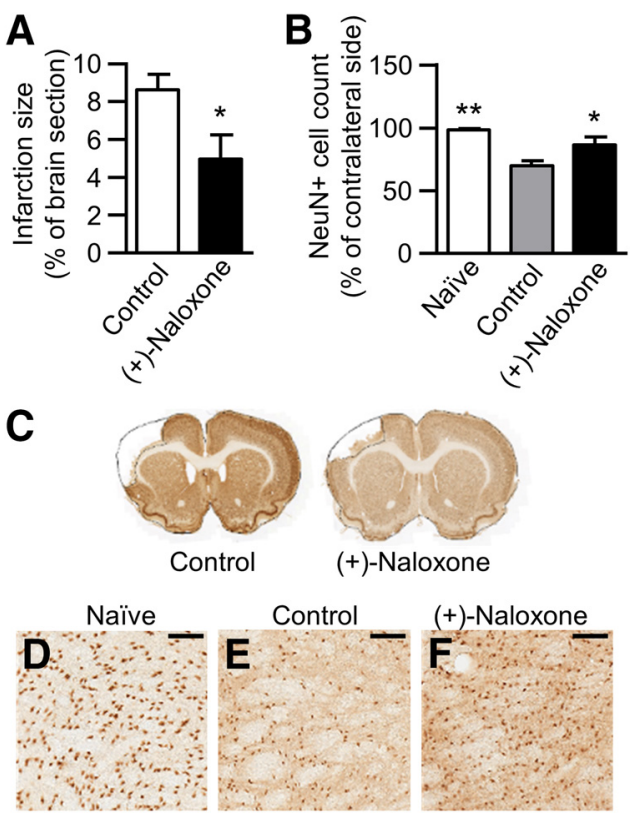

Figure 6. Post-stroke intranasal (+)-naloxone decreases infarction area and neuronal loss in the thalamus. $\boldsymbol{A}$, Average infarction size calculated from NeuN-negative area at day 14 post-stroke. $*, p<0.05$, Student's $t$ test. $\boldsymbol{B}$, Average number of neurons $\left(\mathrm{NeuN}^{+}\right.$cells) in the ipsilateral thalamus at day 14 post-stroke expressed as a percentage of the contralateral thalamus. $*, p<0.05$ and $* *, p<0.01$ indicate pairwise comparison with the control group with Mann-Whitney $U$ test following Kruskal-Wallis test. $\boldsymbol{C}$, Representative photomicrographs of antiNeuN immunostained brain sections, with infarction area delineated. $\boldsymbol{D}-\boldsymbol{F}$, Representative photomicrographs of anti-NeuN immunostaining of ipsilateral thalamus in naive $(\boldsymbol{D})$, control $(\boldsymbol{E})$, and $(+)$-naloxone-treated $(\boldsymbol{F})$ rats. Scale bar is $150 \mu \mathrm{m}$. Naive, no-stroke rats $(n=6)$; control, stroke rats with vehicle or no treatment $(n=18) ;(+)$-naloxone, $0.32-0.8 \mathrm{mg} / \mathrm{kg}(n=10)$. The data represent mean \pm SEM

expansion that occurs up to 24-48 $\mathrm{h}$ after transient MCAo (Li et al., 2000; Liu et al., 2009). This is further supported by the fact that (+)-naloxone treatment starting on days $2-3$ post-stroke did not have a significant effect on recovery. Thus, the therapeutic window for (+)-naloxone seems to be between 16 and $36 \mathrm{~h}$ post-stroke, when there is not yet substantial activation of microglia. However, when using mini-osmotic pumps, the drug kinetics and concentrations at the target tissues over the administration period are only estimations until quantitative assessments of delivery are performed. When the intranasal $(+)$-naloxone treatment was started at day 3 post-stroke and continued for $7 \mathrm{~d}$, there was a trend for milder neurologic deficits on day 16 post-stroke $(p=$ 0.066). Because of the small number of animals, the data are inconclusive and further studies are needed to fully optimize the dosing and timing of administration. Yet, prestroke treatment with $(+)$-naloxone was not neuroprotective, as has been shown before by Liao et al. (2003), supporting our hypothesis that (+)-naloxone should be administered during the inflammation period.

We also show that naloxone enantiomers decrease unstimulated TNF- $\alpha$ secretion from microglia/macro- phages isolated from the stroke cortex at day 7 poststroke. Although the characteristics and phenotypes of microglia are altered in in vitro conditions (Gosselin et al., 2017), these data strengthen the view that (+)-naloxone can regulate the pro-inflammatory function of microglia/ macrophages. Moreover, microglia phenotype is highly dependent on the environment where it is, and therefore the data should be interpreted carefully. It is noteworthy that this study is the first to show that $(-)$ - or (+)-naloxone inhibits basal TNF- $\alpha$ secretion from stroke-activated microglia/macrophages without extra stimulus.

The time course of microglial and astrocyte activation in the thalamus after cortical stroke is less studied. We observed activated microglia/macrophages and increased GFAP immunoreactivity in the thalamus still at 4 mo poststroke, and indeed, also in the intraluminal MCAo model microglial activation in the thalamus has been reported to be long-lasting, for up to 6 mo post-stroke (Justicia et al., 2008). However, in the intraluminal MCAo model, the ischemic lesion is somewhat close to the thalamus and in some cases extends into it. Microglia and astrocytes have been shown to be activated already after day 3 poststroke in the ipsilateral thalamus in the transient intraluminal MCAo model (Loos et al., 2003). In our model, microglial and astrocyte activation was evident in the ipsilateral thalamus at $7 \mathrm{~d}$ post-stroke, but interestingly, microglia were not phagocytic until day 14. Previously, it has been reported that neuronal degeneration in the ipsilateral thalamus is evident at $14 \mathrm{~d}$ post-stroke in the transient intraluminal MCAo model (Loos et al., 2003), similar to our findings. The ischemia-induced neuronal loss and microglia/macrophage activation in the thalamus probably reflects retrograde/anterograde degeneration caused by cortical damage. However, inflammation has been implicated in secondary neurodegeneration (Block et al., 2005; Schroeter et al., 2006), and (+)-naloxone reduces inflammation and neurodegeneration at both primary (cortex) and secondary (thalamus) sites of injury. Although it remains unclear whether the beneficial effects of $(+)$-naloxone occur directly in cells in the thalamus or indirectly by reducing inflammation in the cortex, or both, intranasal (+)-naloxone is apparently beneficial to recovery from stroke. The thalamus regulates multiple sensory and motor functions that are also controlled by other brain regions. Furthermore, the thalamus is a relay station connecting the right and left hemispheres, and a unilateral lesion of the thalamus usually has little behavioral consequences (Carrera and Bogousslavsky, 2006). Overall, the role of thalamic neurodegeneration and inflammation following cortical infarction remains unclear, and it is not known whether the secondary pathology affects behavioral recovery. Our study supports the need for future research into the role of thalamic injury in cortical stroke.

Single (+)-naloxone doses that had effect on recovery in our study were $0.08 \mathrm{mg} / \mathrm{kg}, 0.32 \mathrm{mg} / \mathrm{kg}$, and $0.8 \mathrm{mg} / \mathrm{kg}$. As a comparison, the FDA-approved Narcan nasal spray to treat opioid overdose contains $4 \mathrm{mg}$ of $(-)$-naloxone hydrochloride, being equivalent to $0.08 \mathrm{mg} / \mathrm{kg}$ dose for a person weighing $50 \mathrm{~kg}$. Based on pharmacokinetic data on naloxone (Dowling et al., 2008; Krieter et al., 2016), we 


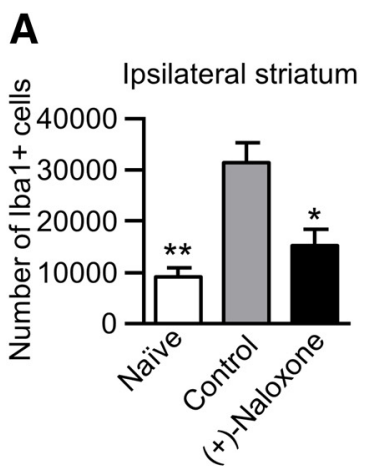

\section{B}

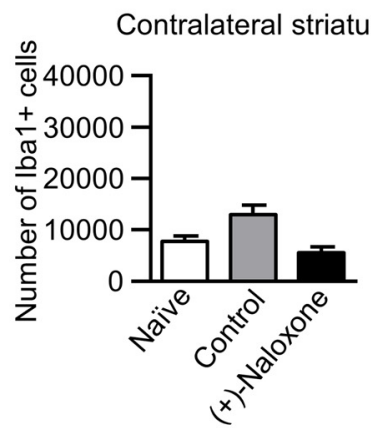

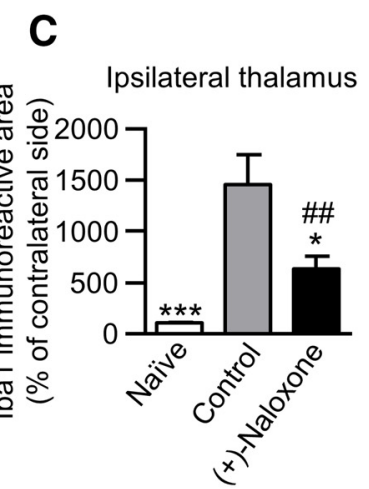
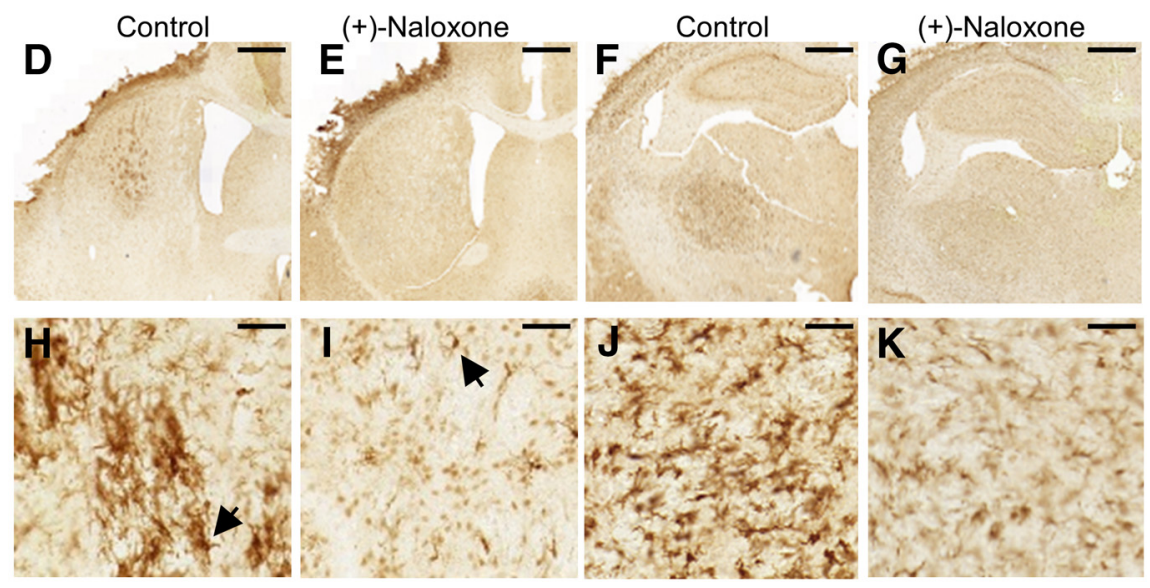

Figure 7. Post-stroke intranasal (+)-naloxone decreases microglia/macrophage activation in the striatum and thalamus. $A, B$, Microglia/macrophages (lba1 ${ }^{+}$cells) were counted with unbiased stereology in the ipsilateral $(\boldsymbol{A})$ and contralateral $(\boldsymbol{B})$ striatum. $*, p$ $<0.05$ and **, $p<0.01$ indicate pairwise comparison with the control group with Bonferroni's post hoc test following one-way ANOVA. $\boldsymbol{C}$, The area of $\mathrm{Iba} 1^{+}$cells in the ipsilateral thalamus expressed as a percentage of the contralateral thalamus. $*, p<0.05$ and $* * *, p<0.001$ indicate pairwise comparison with the control group; \#\#, $p<0.01$ indicates comparison with the naive group with Mann-Whitney $U$ test following Kruskal-Wallis test. $\boldsymbol{D}-\boldsymbol{K}$, Representative photomicrographs of anti-lba1 immunostaining of ipsilateral striatum $(\boldsymbol{D}, \boldsymbol{E})$ and thalamus $(\boldsymbol{F}, \boldsymbol{G})$ in control $(\boldsymbol{D}, \boldsymbol{F})$ and $(+)$-naloxone-treated $(\boldsymbol{E}, \boldsymbol{G})$ rats; $\boldsymbol{H}-\boldsymbol{K}$ show high magnification. Black arrow shows a typical Iba1 ${ }^{+}$cell. Scale bars are $1000 \mu \mathrm{m}(\boldsymbol{D}-\boldsymbol{G})$ and $50 \mu \mathrm{m}(\boldsymbol{H}-\boldsymbol{K})$. Naive, no-stroke rats $(n=6)$; control, stroke rats with vehicle or no treatment $(n=18) ;(+)$-naloxone, $0.32-0.8 \mathrm{mg} / \mathrm{kg}(n=10)$. The data represent mean \pm SEM.

estimated that $(+)$-naloxone levels in rat brain reached nanomolar concentrations. The pharmacokinetic profile of naloxone is favorable for stroke treatment, since it is efficiently transported to the brain. However, its short elimination half-life [1.57 $\pm 0.784 \mathrm{~h}$ (Lewis et al., 2012)] requires repeated dosing. Short-term (up to $2 \mathrm{~d}$ poststroke) intravenous (-)-naloxone (dose from 0.4 to $4 \mathrm{mg}$ ) has been tested in patients having an acute ischemic stroke, and it has rapidly, within minutes, improved neurologic deficits (Baskin and Hosobuchi, 1981; Jabaily and Davis, 1984). However, later clinical studies on the efficacy of naloxone have been inconclusive. A phase II open trial studying the safety of a high loading dose followed by 24-h infusion of (-)-naloxone did not find benefit at 3 mo post-stroke when the treatment was started within $48 \mathrm{~h}$ of stroke onset (Olinger et al., 1990). A subsequent doubleblind, randomized pilot trial using the 24-h infusion found no significant differences between the naloxone and placebo groups when the treatment was initiated within $12 \mathrm{~h}$ of the onset of symptoms (Federico et al., 1991). At the time when these studies were performed, the antiinflammatory effects of naloxone were not known. The lack of effect in these clinical studies may have resulted from the short treatment regimen. Treatment for only $24 \mathrm{~h}$ may not be enough to dampen the post-stroke microglial response. Moreover, the clinical studies have been based on the assumption that opioid antagonism is at least partly behind the beneficial effect of naloxone in acute stroke that was reported in the early case studies in the 1980s. In our experiment, both (+)- and (-)-naloxone had a similar effect on recovery starting from post-stroke day 10 onward, implying that opioid receptor antagonism is not necessary for the recovery promoting effect in the chronic phase of stroke. Thus, we propose additional clinical studies that would use different dosing paradigms to optimize the post-stroke (+)-naloxone dosing regimen.

The Stroke Therapy Academic Industry Roundtable (STAIR) recommendations to improve the quality of preclinical stroke studies emphasize the importance of doseresponse and therapeutic window studies together with histologic and functional outcome monitoring. According to STAIR recommendations, the therapies should be tested in several animal species using both sexes as well as aged and comorbid animals. Therefore, we warrant further studies using (+)-naloxone for stroke treatment in female, aged, and comorbid animals to better reflect the 
A

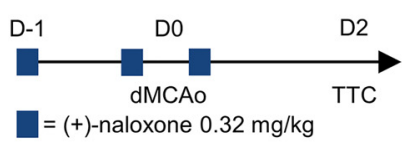

B

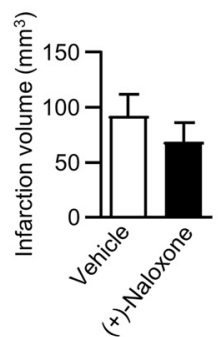

C

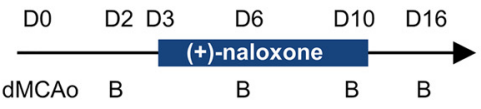

D

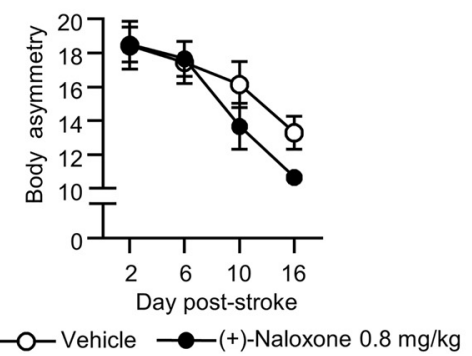

E

\begin{tabular}{cccccc} 
D0 & D2 & D4 & D8 & D11 & D14 \\
\hline dMCAo & B & B & (+)-naloxone & \\
B & B & B
\end{tabular}

F

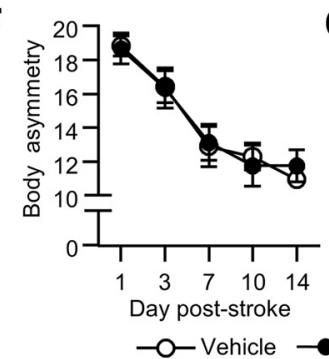

G

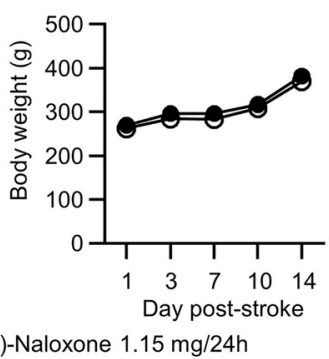

Figure 8. Effect of different pre- and post-stroke treatment with (+)-naloxone on infarct volume and functional recovery. $A$, Experimental timeline. Intranasal (+)-naloxone or vehicle was administered three times: 12 and $1 \mathrm{~h}$ before dMCAo and immediately after reperfusion. Infarction volume was determined by TTC staining $2 \mathrm{~d}$ after stroke. $\boldsymbol{B}$, Average infarction volume $\left(\mathrm{mm}^{3}\right)$ on day 2 post-stroke in vehicle $(n=7)$ and $(+)$-naloxone $(0.32 \mathrm{mg} / \mathrm{kg} ; n=8)$ pretreated rats. Prestroke intranasal administration of $(+)$-naloxone was not neuroprotective in 60-min dMCAo. C. Experimental timeline. (+)-Naloxone was delivered intranasally twice daily for $7 \mathrm{~d}$ post-stroke starting from post-stroke day 3. $\boldsymbol{D}$, The effect of $(+)$-naloxone $(0.8 \mathrm{mg} / \mathrm{kg} ; n=6)$ and vehicle $(n=7)$ treatment from post-stroke day 3 to post-stroke day 10 on body asymmetry test. $\boldsymbol{E}$, Experimental timeline. $(+)$-Naloxone was delivered into the ventricle via mini-osmotic pumps for $12 \mathrm{~d}$ post-stroke starting from post-stroke day 2 . $\boldsymbol{F}, \boldsymbol{G}$, The effects of 12 -d continuous delivery of (+)-naloxone $(1.15 \mathrm{mg} / 24 \mathrm{~h} ; n=7)$ and vehicle $(n=8)$ on body asymmetry test $(\boldsymbol{F})$ and body weight $(\boldsymbol{G})$. In $\boldsymbol{A}, \boldsymbol{C}$, and $\boldsymbol{E}$ : D, indicated post-stroke day; $\mathrm{B}$, behavioral assay. The data represent mean \pm SEM.

clinical situation within the heterogeneous patient population. Also, behavioral testing should be conducted for $>14 \mathrm{~d}$ to confirm the beneficial effect of $(+)$-naloxone on long-term behavioral recovery. Regarding the safety of naloxone therapy, naloxone has been already shown to be safe and well tolerated in patients with the corresponding dose range we have been using in rats.

In conclusion, characterization of the neuroinflammatory response in rat cortical stroke revealed long-lasting microglia/macrophage and astrocyte activation as well as neuronal death in the ipsilateral thalamus. Phagocytic
A

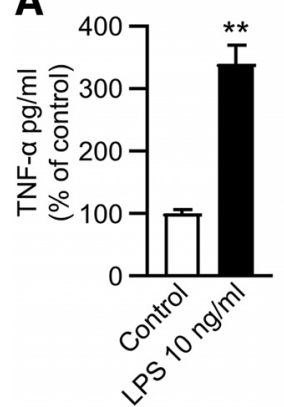

B

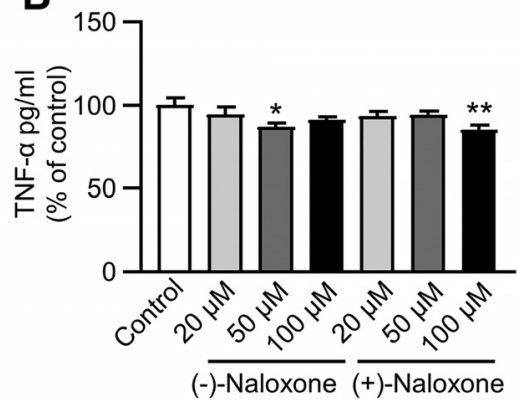

Figure 9. Naloxone reduced TNF- $\alpha$ secretion from $\mathrm{CD}_{11 \mathrm{~b}^{+}}$ cells. $\boldsymbol{A}$, LPS induced TNF- $\alpha$ secretion from CD11b-expressing cells isolated from the infarct area of rat brain $7 \mathrm{~d}$ after dMCAo. $* *, p<0.01$, Mann-Whitney $U$ test; control $n=6$, LPS $n=5$ in 2 independent experiments. $\boldsymbol{B}, \mathrm{CD} 11 \mathrm{~b}^{+}$cells were isolated from the infarct area and treated with different concentrations of naloxone as indicated for 20 h. $*, p<0.05$ and $* *, p<0.01$ indicate pairwise comparison with the control group by Dunnett's post hoc test following one-way ANOVA; control $n=9$, naloxone $n=8-9$ in 3 independent experiments. The culture medium was analyzed using TNF- $\alpha$ ELISA. The data represent mean \pm SEM. cells were present in the thalamus for up to 4 mo poststroke. This delayed neuronal loss and phagocytosis in the thalamus could serve as a new target for drug treatment after stroke with a larger therapeutic window than exists for current post-stroke treatment (i.e., tissue plasminogen activator). Most importantly, we found that intermittent post-stroke intranasal $(+)$-naloxone treatment starting on day 1 post-stroke promoted short-term behavioral recovery, reduced microglial activation in the striatum and thalamus, and decreased neuronal loss in the cortex and thalamus. It is likely that $(+)$-naloxone mediates its positive effects on stroke via mechanisms where TLR signaling and reduction of oxidative stress are involved. (+)-Naloxone is thus a promising drug for the treatment of ischemic stroke.

\section{References}

Airavaara M, Chiocco MJ, Howard DB, Zuchowski KL, Peränen J, Liu C, Fang S, Hoffer BJ, Wang Y, Harvey BK (2010) Widespread cortical expression of MANF by AAV serotype 7: localization and protection against ischemic brain injury. Exp Neurol 225:104-113. CrossRef

Airavaara M, Shen H, Kuo CC, Peränen J, Saarma M, Hoffer B, Wang $Y$ (2009) Mesencephalic astrocyte-derived neurotrophic factor reduces ischemic brain injury and promotes behavioral recovery in rats. J Comp Neur 515:116-124. CrossRef Medline

Atkinson RL (1984) Endocrine and metabolic effects of opiate antagonists. J Clin Psychiatry 45:20-24. Medline

Baskin DS, Hosobuchi Y (1981) Naloxone reversal of ischaemic neurological deficits in man. Lancet 2:272-275. Medline

Bederson JB, Pitts LH, Tsuji M, Nishimura MC, Davis RL, Bartkowski H (1986) Rat middle cerebral artery occlusion: evaluation of the model and development of a neurologic examination. Stroke 17: 472-476. Medline

Block F, Dihné M, Loos M (2005) Inflammation in areas of remote changes following focal brain lesion. Prog Neurobiol 75:342-365. CrossRef Medline 
Block ML, Zecca L, Hong JS (2007) Microglia-mediated neurotoxicity: uncovering the molecular mechanisms. Nat Rev Neurosci 8:57-69. CrossRef Medline

Borlongan CV, Tajima Y, Trojanowski JQ, Lee VM, Sanberg PR (1998) Cerebral ischemia and CNS transplantation: differential effects of grafted fetal rat striatal cells and human neurons derived from a clonal cell line. Neuroreport 9:3703-3709. Medline

Carrera E, Bogousslavsky J (2006) The thalamus and behavior: effects of anatomically distinct strokes. Neurology 66:1817-1823. CrossRef Medline

Chen CJ, Liao SL, Chen WY, Hong JS, Kuo JS (2001) Cerebral ischemia/reperfusion injury in rat brain: effects of naloxone. Neuroreport 12:1245-1249. Medline

Chen ST, Hsu CY, Hogan EL, Maricq H, Balentine JD (1986) A model of focal ischemic stroke in the rat: reproducible extensive cortical infarction. Stroke 17:738-743. Medline

Delavaran $\mathrm{H}$, Sjunnesson H, Arvidsson A, Lindvall O, Norrving B, van Westen D, Kokaia Z, Lindgren A (2013) Proximity of brain infarcts to regions of endogenous neurogenesis and involvement of striatum in ischaemic stroke. Eur J Neurol 20:473-479. CrossRef Medline

Dirnagl U (2012) Pathobiology of injury after stroke: the neurovascular unit and beyond. Ann N Y Acad Sci 1268:21-25. CrossRef Medline

Dirnagl U, ladecola C, Moskowitz MA (1999) Pathobiology of ischaemic stroke: an integrated view. Trends Neurosci 22:391-397. Medline

Dowling J, Isbister GK, Kirkpatrick CM, Naidoo D, Graudins A (2008) Population pharmacokinetics of intravenous, intramuscular, and intranasal naloxone in human volunteers. Ther Drug Monit 30:490496. CrossRef Medline

Endres M, Engelhardt B, Koistinaho J, Lindvall O, Meairs S, Mohr JP, Planas A, Rothwell N, Schwaninger M, Schwab ME, Vivien D, Wieloch T, Dirnagl U (2008) Improving outcome after stroke: overcoming the translational roadblock. Cerebrovasc Dis 25:268-278. CrossRef Medline

Federico F, Lucivero V, Lamberti P, Fiore A, Conte C (1991) A double blind randomized pilot trial of naloxone in the treatment of acute ischemic stroke. Ital J Neurol Sci 12:557-563. Medline

Glass CK, Saijo K, Winner B, Marchetto MC, Gage FH (2010) Mechanisms underlying inflammation in neurodegeneration. Cell 140: 918-934. CrossRef Medline

Gosselin D, Skola D, Coufal NG, Holtman IR, Schlachetzki JCM, Sajti E, Jaeger BN, O'Connor C, Fitzpatrick C, Pasillas MP, Pena M, Adair A, Gonda DD, Levy ML, Ransohoff RM, Gage FH, Glass CK (2017) An environment-dependent transcriptional network specifies human microglia identity. Science 356:eaal3222. CrossRef

Harvey BK, Airavaara M, Hinzman J, Wires EM, Chiocco MJ, Howard DB, Shen H, Gerhardt G, Hoffer BJ, Wang Y (2011) Targeted over-expression of glutamate transporter 1 (GLT-1) reduces ischemic brain injury in a rat model of stroke. PLoS One 6:e22135. CrossRef

Hutchinson MR, et al. (2012) Opioid activation of toll-like receptor 4 contributes to drug reinforcement. J Neurosci 32:11187-11200. CrossRef Medline

Hutchinson MR, Zhang Y, Brown K, Coats BD, Shridhar M, Sholar PW, Patel SJ, Crysdale NY, Harrison JA, Maier SF, Rice KC, Watkins LR (2008) Non-stereoselective reversal of neuropathic pain by naloxone and naltrexone: involvement of toll-like receptor 4 (TLR4). Eur J Neurosci 28: 20-29. CrossRef Medline

lijima I, Minamikawa J, Jacobson AE, Brossi A, Rice KC (1978) Studies in the $(+)$-morphinan series. 5 . Synthesis and biological properties of (+)-naloxone. J Med Chem 21:398-400. Medline

Jabaily J, Davis JN (1984) Naloxone administration to patients with acute stroke. Stroke 15:36-39. Medline

Justicia C, Ramos-Cabrer P, Hoehn M (2008) MRI detection of secondary damage after stroke: chronic iron accumulation in the thalamus of the rat brain. Stroke 39:1541-1547. CrossRef Medline

Kilic U, Kilic E, Matter CM, Bassetti CL, Hermann DM (2008) TLR-4 deficiency protects against focal cerebral ischemia and axotomy- induced neurodegeneration. Neurobiol Dis 31:33-40. CrossRef Medline

Krieter P, Chiang N, Gyaw S, Skolnick P, Crystal R, Keegan F, Aker J, Beck M, Harris J (2016) Pharmacokinetic properties and human use characteristics of an FDA-approved intranasal naloxone product for the treatment of opioid overdose. J Clin Pharmacol 56: 1243-1253. CrossRef Medline

Lee SC, Liu W, Dickson DW, Brosnan CF, Berman JW (1993) Cytokine production by human fetal microglia and astrocytes. Differential induction by lipopolysaccharide and IL-1 beta. J Immunol 150:2659-2667. Medline

Lehnardt S, Massillon L, Follett P, Jensen FE, Ratan R, Rosenberg PA, Volpe JJ, Vartanian T (2003) Activation of innate immunity in the CNS triggers neurodegeneration through a Toll-like receptor 4-dependent pathway. Proc Natl Acad Sci U S A 100:8514-8519. CrossRef

Lewis SS, Loram LC, Hutchinson MR, Li CM, Zhang Y, Maier SF, Huang Y, Rice KC, Watkins LR (2012) (+)-Naloxone, an opioidinactive toll-like receptor 4 signaling inhibitor, reverses multiple models of chronic neuropathic pain in rats. J Pain 13:498-506. CrossRef Medline

Li F, Silva MD, Sotak CH, Fisher M (2000) Temporal evolution of ischemic injury evaluated with diffusion-, perfusion-, and T2weighted MRI. Neurology 54:689-696. Medline

Liao SL, Chen WY, Raung SL, Chen CJ (2003) Neuroprotection of naloxone against ischemic injury in rats: role of mu receptor antagonism. Neurosci Lett 345:169-172. Medline

Liebigt S, Schlegel N, Oberland J, Witte OW, Redecker C, Keiner S (2012) Effects of rehabilitative training and anti-inflammatory treatment on functional recovery and cellular reorganization following stroke. Exp Neurol 233:776-782. CrossRef Medline

Liu B, Du L, Hong JS (2000a) Naloxone protects rat dopaminergic neurons against inflammatory damage through inhibition of microglia activation and superoxide generation. J Pharmacol Exp Ther 293:607-617.

Liu B, Du L, Kong LY, Hudson PM, Wilson BC, Chang RC, Abel HH, Hong JS (2000b) Reduction by naloxone of lipopolysaccharideinduced neurotoxicity in mouse cortical neuron-glia co-cultures. Neuroscience 97:749-756. CrossRef

Liu B, Jiang JW, Wilson BC, Du L, Yang SN, Wang JY, Wu GC, Cao $X D$, Hong JS (2000c) Systemic infusion of naloxone reduces degeneration of rat substantia nigral dopaminergic neurons induced by intranigral injection of lipopolysaccharide. J Pharmacol Exp Ther 295:125-132.

Liu F, Schafer DP, McCullough LD (2009) TTC, fluoro-Jade B and NeuN staining confirm evolving phases of infarction induced by middle cerebral artery occlusion. J Neurosci Methods 179:1-8. CrossRef Medline

Liu Y, Qin L, Wilson BC, An L, Hong JS, Liu B (2002) Inhibition by naloxone stereoisomers of beta-amyloid peptide (1-42)-induced superoxide production in microglia and degeneration of cortical and mesencephalic neurons. J Pharmacol Exp Ther 302:12121219. CrossRef

Loos M, Dihné M, Block F (2003) Tumor necrosis factor-alpha expression in areas of remote degeneration following middle cerebral artery occlusion of the rat. Neuroscience 122:373-380. Medline

Luo Y, Shen H, Liu HS, Yu SJ, Reiner DJ, Harvey BK, Hoffer BJ, Yang Y, Wang Y (2013) CART peptide induces neuroregeneration in stroke rats. J Cereb Blood Flow Metab 33:300-310. CrossRef Medline

Mijatovic J, Airavaara M, Planken A, Auvinen P, Raasmaja A, Piepponen TP, Costantini F, Ahtee L, Saarma M (2007) Constitutive Ret activity in knock-in multiple endocrine neoplasia type B mice induces profound elevation of brain dopamine concentration via enhanced synthesis and increases the number of TH-positive cells in the substantia nigra. J Neurosci 27:4799-4809. CrossRef Medline

Neher JJ, Emmrich JV, Fricker M, Mander PK, Thery C, Brown GC (2013) Phagocytosis executes delayed neuronal death after focal brain ischemia. Proc Natl Acad Sci U S A 110:E4098-E4107. CrossRef 
Olinger CP, Adams HP, Jr, Brott TG, Biller J, Barsan WG, Toffol GJ, Eberle RW, Marler JR (1990) High-dose intravenous naloxone for the treatment of acute ischemic stroke. Stroke 21:721-725. Medline

Qin L, Block ML, Liu Y, Bienstock RJ, Pei Z, Zhang W, Wu X, Wilson B, Burka T, Hong JS (2005) Microglial NADPH oxidase is a novel target for femtomolar neuroprotection against oxidative stress. Faseb J 19:550-557. CrossRef

Schroeter M, Zickler P, Denhardt DT, Hartung HP, Jander S (2006) Increased thalamic neurodegeneration following ischaemic cortical stroke in osteopontin-deficient mice. Brain 129:1426-1437. CrossRef Medline

Wang Q, Zhou H, Gao H, Chen SH, Chu CH, Wilson B, Hong JS (2012) Naloxone inhibits immune cell function by suppressing superoxide production through a direct interaction with gp91phox subunit of NADPH oxidase. J Neuroinflammation 9:32. CrossRef Medline

Wang X, Zhang Y, Peng Y, Hutchinson MR, Rice KC, Yin H, Watkins LR (2016) Pharmacological characterization of the opioid inactive isomers (+)-naltrexone and (+)-naloxone as antagonists of Tolllike receptor 4. Br J Pharmacol 173:856-869. CrossRef Medline Yang QW, Li JC, Lu FL, Wen AQ, Xiang J, Zhang LL, Huang ZY, Wang JZ (2008) Upregulated expression of Toll-like receptor 4 in monocytes correlates with severity of acute cerebral infarction. J Cereb Blood Flow Metab 28:1588-1596. CrossRef Medline

Yrjanheikki J, Tikka T, Keinanen R, Goldsteins G, Chan PH, Koistinaho $J$ (1999) A tetracycline derivative, minocycline, reduces inflammation and protects against focal cerebral ischemia with a wide therapeutic window. Proc Natl Acad Sci U S A 96:1349613500. CrossRef 